\title{
Administración y enajenación de bienes temporales eclesiásticos a la luz del Concilio Vaticano II. Parte II: Lumen Gentium, cap. VI; Presbyterorum Ordinis n. ${ }^{\circ} 17$, y Perfectae Caritatis n. ${ }^{\circ} 13^{*}$
}

\author{
Administration and Alienation of Temporary Ecclesiastic Properties according to the $2^{\text {nd }}$ Vatican Council. Part II: \\ Lumen Gentium, Cap. VI; Presbyterorum Ordinis no. 17 and Perfectae Caritatis no. 13
}

Ismael Arturo Garceranth Ramos ${ }^{\text {a }}$

Pontificia Universidad Javeriana, Colombia

DOI: https://doi.org/10.11144/Javeriana.ucan35-51.aebt igarcerant@javeriana.edu.co

ORCID: https://orcid.org/0000-0002-1281-3450

Recibido: 30 Octubre 2018

Aceptado: 30 Noviembre 2018

Publicado: 30 Diciembre 2018

\section{Resumen:}

Los documentos conciliares Lumen Gentium, Presbyterorum Ordinis y Perfectae Caritatis fueron fuente para la posterior elaboración de ciertos cánones del Código de Derecho Canónico (CIC, por sus siglas en latín) (Juan Pablo II, 1983) referidos a la administración y enajenación de bienes eclesiásticos, en especial de aquellos pertenecientes a los institutos religiosos.

Este artículo se ubica dentro del Libro V del CIC (Juan Pablo II, 1983) y guarda relación y continuidad con otros artículos del mismo autor que también nacieron del Libro en mención. Estos artículos han sido publicados en revistas anteriores de esta colección de Universitas Canonica. De manera particular, se destaca la primera parte del presente artículo, titulado "Administración y enajenación de bienes temporales eclesiásticos de institutos religiosos a la luz del Concilio Vaticano II: Lumen Gentium, cap. VI, Presbyterorum Ordinis no. 17 y Perfectae Caritatis no. 13" (Parte I), en el que se aborda el tema en mención y su relación con el decreto Presbyterorum Ordinis no. 17.

Continuando con esta temática, y para un segundo momento, en el presente artículo estudiaremos el Capítulo VI de la Constitución Dogmática Lumen Gentium y, finalmente, en un tercer artículo, con el mismo fin y la misma metodología, analizaremos el no. 13 del decreto Perfectae Caritatis.

Palabras clave: Concilio Vaticano II, Constitución Dogmática Lumen Gentium (capítulo VI), Instituto Religioso.

\section{Abstract:}

The 2nd Council documents Lumen Gentium, Presbyterorum Ordinis and Perfectae Caritatis were a source for developing some canons of the Canon Law Code (CIC, Latin acronym) (John Paul II, 1983) dealing with the administration and alienation of ecclesiastic properties, especially those owned by religious institutes. This article studies a part of the Book V in the CIC (John Paul II, 1983) and is connected and continues the work developed in other articles by the same author, which also addressed the said Book. These articles were published in previous journals of this collection Universitas Canonica. In particular, the first of this article is notorious; the title "Administration and Alienation of Temporary Ecclesiastic Properties Owned by Religious Institutes according to the Second Vatican Council: Lumen Gentium, Chap. VI, Presbyterorum Ordinis no. 17 and Perfectae Caritatis no. 13" (Part I) indicates the topic addressed therein and its relation to the decree Presbyterorum Ordinis no. 17. Next part of this article explores Chapter VI of the Dogmatic Constitution Lumen Gentiu. Finally, the third part, with the same aim and methodology, analyzes no. 13 of the decree Perfectae Caritatis.

Keywords: Second Vatican Council, Dogmatic Constitution Lumen Gentium (Chapter VI), religious institute.

\section{Introducción}

El tema de la administración y la enajenación de bienes temporales de personas jurídicas públicas en la Iglesia católica puede estudiarse desde diferentes puntos de vista. Si se parte del Libro V y demás cánones concordantes del CIC (Juan Pablo II, 1983), dicho estudio podría hacerse a la luz de algunos textos del

Notas de autor

a Autor de correspondencia: correo electrónico: igarcerant@javeriana.edu.co 
Concilio Vaticano II que estuvieron a la base y fueron fuente de elaboración y redacción de la nueva legislación canónica.

Entre los diferentes documentos conciliares existen tres que resultan especialmente importantes para abordar el tema de la administración y enajenación de bienes temporales eclesiásticos de institutos religiosos $^{[1]}$ : el capítulo VI de la Constitución Dogmática, sobre la Iglesia (Lumen Gentium), el no. 17 del decreto Presbyterorum Ordinis, sobre el ministerio y vida de los presbíteros (Garceranth Ramos, 2011), y el no. 13 del decreto Perfectae Caritatis, sobre la adecuada renovación de la vida religiosa (Conciliorum Oecumenicorum Decreta, 2000; Caprile, 1965-1966) ${ }^{[2]}$.

El estudio de estos tres documentos conciliares se realizará bajo la ayuda del método históricohermeneutico; en consecuencia, y de manera específica, aplicaremos la metodología en mención en el estudio y elaboración del presente artículo sobre la administración y enajenación de bienes temporales de institutos religiosos, a la luz del capítulo VI de la Constitución Dogmática Lumen Gentium.

Cabe agregar que el documento final de este texto fue el resultado de un proceso bastante complejo.

En un primer momento será necesario conocer, grosso modo, el proceso histórico de elaboración del capítulo V de la Constitución Dogmática, para así resaltar algunos aspectos importantes, sin que con ello se logre agotar su iter. Un segundo momento nos exige reconocer, señalar y comprender los elementos constitutivos del documento conciliar en mención, los cuales fueron el fruto de discusiones que se presentaron en el proceso de su elaboración. Por último, un tercer lugar nos llevará a concluir el sentido, alcance e incidencia del capítulo VI de la Lumen Gentium en la legislación canónica.

En virtud de lo dicho, el objetivo general del presente estudio será conocer la incidencia del Concilio Vaticano II en relación con la administración y enajenación de bienes temporales eclesiásticos de institutos religiosos. Para esto nos apoyados en los textos conciliares indicados.

El análisis del capítulo VI de la Lumen Gentium en cuanto a su proceso histórico de elaboración, los elementos constitutivos y las conclusiones finales se constituyen como los objetivos específicos del presente estudio.

\section{Aspectos comunes de algunos textos concilares}

El Lumen Gentium capítulo VI, el Presbyterorm Ordinis no. 17 y el Perfectae Caritatis no. 13 tienen una fuente histórica común en sus orígenes, pero fue su desarrollo lo que les permitió individualizarse. Ante el anuncio del Papa Juan XXIII (1959), hecho el 25 de enero de 1959, de querer celebrar un Concilio Ecuménico el 17 de mayo, día de la fiesta de Pentecostés, el Romano Pontífice Padre constituyó la Commissione Conciliare Antepreparatoria ${ }^{[3]}$.

En cumplimiento de su encargo, el 18 de junio del mismo año, su presidente, el cardenal Tardini, envió carta a 2594 obispos y prelados ${ }^{[4]}$, a 156 superiores generales y, un mes después, a las universidades católicas ${ }^{[5]}$ con el propósito de que presentaran propuestas en materia dogmática, bíblica, litúrgica, psicológica, moral, jurídica, pastoral y social, etc., que consideraran oportunas para ser tratadas durante el futuro concilio y que tuvieron el fin de aggiornar la Iglesia a las necesidades del mundo.

Las respuestas no tardaron en llegar ${ }^{[6]}$ : las de los obispos y prelados se recogieron en siete tomos ${ }^{[7]}$ y las de los superiores generales en uno ${ }^{[8]}$, este material fue compilado en un Appendix de dos tomos ${ }^{[9]}$. Las propuestas de las universidades se reunieron en tres tomos ${ }^{[10]}$ y las propuestas y comentarios de las congregaciones de la Curia Romana en uno ${ }^{[11]}$. Un volumen de índice se une a esta lista de los documentos reunidos durante la etapa antepreparatoria del Concilio ${ }^{[12]}$.

Las respuestas recibidas fueron organizadas según la materia y después enviadas a los dicasterios competentes $^{[13]}$, para que también formularan los postulados que consideraran necesarios. 
Así, la etapa antepreparatoria del Concilio mostró los intereses, las problemas o situaciones que se presentaban en la Iglesia en ese momento histórico, lo que permitió leer, al menos in nuce, aspectos después desarrollados en cada uno de los documentos conciliares.

\section{Capítulo VI de la Constitución Dogmática Lumen Gentium}

La Constitución Dogmática Lumen Gentium, considerado el documento pilar del Concilio (Vaticano II, 1964, p. 21), dio fundamento al tema de los religiosos. En el capítulo VI ofrece una reflexión que muestra la importancia y el sentido de esta forma de vida en la Iglesia. Si bien su proceso de elaboración fue complejo ${ }^{[14]}$, su resultado ayudó a las familias religiosas a renovarse y a vivir una mayor identidad de su ser a la luz del carisma de cada Instituto (Beyer, 1975, p. 845).

\section{Desarrollo histórico}

\section{Etapas antepreparatoria y preparatoria}

Entre las propuestas recibidas por la Comisión Antepreparatoria ${ }^{[15]}$ muchas pedían tratar el tema $D e$ Ecclesia $^{[16]}$, por lo que, dentro de ella, la vida religiosa reclamaba un lugar ${ }^{[17]}$ a fin de estudiar ciertos aspectos propios de esta forma de ser que requerían de mayor claridad. Desde esta primera fase el tema de los religiosos pedía ser objeto de discusiones y decisiones.

Con el Motu Proprio Superno Dei nutu del 5 de junio de 1960, Juan XXIII dispuso que el Concilio Ecuménico se llamaría Vaticano II, además reconoció el trabajo realizado por la Comisión Antepreparatoria, la cual ordenó y catalogó el material recibido de todos los interpelados. De igual forma, el Pontífice creó una Comisión Preparatoria Central y diez Comisiones Preparatorias para asuntos diversos, al interior de las cuales se formaron subcomisiones según las necesidades ${ }^{[18]}$. La Comisión Preparatoria Teológica o Dogmática determinó algunos puntos que debían tenerse en cuenta al momento de elaborar el documento sobre la Iglesia, este sería elaborado por la Subcomisión De Ecclesia, tarea que inició el 26 de noviembre de 1960.

Por su parte, la Comisión Preparatoria De Religiosis pidió que se tuviera en cuenta el tema de la vida religiosa dentro de la Constitución sobre la Iglesia, propuesta que era importante por ser la primera vez que se trataría el sentido teológico de tal materia en una Constitución Dogmática (Molinari y Gumpel), con lo que se superarían los documentos conciliares disciplinares dados para los religiosos en otros tiempos (Lio).

En marzo de 1962, la Subcomisión De Ecclesia produjo un documento amplio y aprobado por la Comisión Preparatoria de los Religiosos y la Comisión Doctrinal. El capítulo V de este documento trataba De statibus evangelicae adquirendae perfectionis ${ }^{[19]}$. El esquema general fue remitido a la Comisión Preparatoria Central, la cual discutió y aprobó, en la sesión del 9 de Mayo ${ }^{[20]}$, bajo el título de Schema Constitutionis Dogmaticae de Ecclesia $^{[21]}$. Por su parte, el capítulo V, "De statibus evangelicae acquirendae perfectionis", abordaba el tema de los religiosos bajo tres numerales: no. 17, De Consiliis evangelicis; no. 18, De momento statuum perfectionis in Ecclesia y no. 19, De positione statuum perfectionis in Ecclesia (Vaticano II, 1970, I/IV, pp. 34-37) ${ }^{[22]}$. El Papa Juan XXIII, en la audiencia del 10 de noviembre de 1962, ordenó el envío de este docuemento a los Padres Conciliares. 


\section{Etapa conciliar}

Periodus Prima: Durante el primer periodo del Concilio, el esquema De Ecclesia fue presentado y discutido del 1.. al 7 de diciembre de 1962 durante las Congregaciones Generales 31-36. Quienes prepararon el texto tuvieron en cuenta que fuera pastoral al máximo, bíblico y comprensible para todos ${ }^{[23]}$.

En cuanto a su contenido, mientras unos Padres solicitaban una revisión del enfoque dado (Vaticano II, 1970, I/IV, pp. 397-639) ${ }^{[24]}$, proponiendo incluso algunos esquemas específicos sobre esta materia ${ }^{[25]}$, otros aceptaban la propuesta hecha por la Comisión Preparatoria Doctrinal. Las reacciones al capítulo V, "De Religiosis", fueron escasas y de poca trascendencia.

Dadas ciertas posiciones encontradas, y sin que se hiciera una votación para conocer la aceptación o no del esquema $D e$ Ecclesia, sino que atendiendo a las intervenciones orales y las propuestas escritas presentadas, el Santo Padre decidió que se redactaría el esquema nuevamente; además, creó una Commissio de Concilii Laboribus Coordinandis encargada de orientar mejor las labores de cada comisión y de estar al tanto de los adelantos en su trabajo (Vaticano II, 1970, I/I, pp. 96-98; Caprile, 1959, p. 258) ${ }^{[26]}$. Esta Comisión de Coordinación se reunió del 21 al 28 de enero de 1963 (Caprile, 1959, p. 326) ${ }^{[27]}$ y señaló parámetros que luego fueron dados a la diferentes Comisiones.

En la primera sesión de esta Comisión de Coordinación, el cardenal Suenens presentó un Schema Constitutionis Doctrinalis de Ecclesia (Vaticano II, 1973, V/I, p. 95) ${ }^{[28]}$ en el que reordenaba el esquema existente y suprimía el capítulo de los religiosos. Ante este hecho, el cardenal Döpfner consideró que no se podía excluir dicho capítulo del esquema De Ecclesia. Al respecto argumentaba que:

El status perfectionis adquirendae es un estado carismático que se origina de la vida y doctrina de Cristo; por institución
eclesiástica tiene su forma jurídica; abraza miembros de ambas formas de institución divina (la jerarquía y los laicos). Está
fundado sobre los consejos evangélicos de pobreza, virginidad y obediencia, que son signos de la redención, los cuales, así
como la vida del Redentor fue marcada por ellos, así también la vida de su Cuerpo místico no puede jamás ser privada de
ella. Estos signos muestran también de modo especial el misterio de la Iglesia, demostrando que en ella la cruz de Cristo
permanece levantada y la comunidad de los redimidos avanza hacia Cristo y hacia la gloria escatológica. Por eso, cuantos son
llamados al estado de perfección, son llamados primeramente no para vivir atendiendo a la propia santificación, sino para
mostrar la naturaleza de la Iglesia y servir a Cristo en ella (y en tal modo conseguir con eso mismo la propia perfección) ${ }^{\text {[29] }}$.
(Vaticano II, 1973, V/I, p. 138)

En la Sessio Prima, Congregatio 7, realizada el 27 de enero de 1963, la Comisión de Coordinación, teniendo como relator al cardenal Suenens, elaboró un esquema De Ecclesia que incluía, en el capítulo IV, a los religiosos bajo el título De statibus evangelicae acquirendae perfectionis ${ }^{[30]}$, allí se reconocía la dimensión cristológica, soteriológica, escatológica y eclesiológica de la vida religiosa.

El esquema De Ecclesia fue remitido a la Comisión Doctrinal, que se reunió en sesión plena del 21 de febrero al 13 de marzo (Caprile, 1959, p. 358), a fin de analizarlo teniendo en cuenta las exigencias del Santo Padre, lo dicho por la Comisión de Coordinación y las sugerencias de los Padres Conciliares. La Comisión Doctrinal creó una subcomisión general De Ecclesia para reelaborar el esquema recibido, el cual debía ser posteriormente presentado a la Comisión Doctrinal y luego a la de Coordinación.

Por su parte, la Comisión de Coordinación consideró oportuno crear una subcomisión mixta, integrada por miembros de las Comisiones Doctrinal y de Religiosos, encargada de tratar el tema de los religiosos; así, esta hizo un esquema titulado De iis que consilia evangelica profitentur que, al ser revisado por la Comisión de Coordinación, retomó el nombre dado en el capítulo IV: "De statibus evangelicae acquirendae perfectionis". El esquema general fue enviado a la Comisión Doctrinal, quien discutió y aprobó los capítulos I, II y III sin mayores novedades, luego, el 23 de marzo y el 25 de mayo de 1963 específicamente, fueron remitidos a las Comisiones correspondientes ${ }^{[31]}$. Para analizar el capítulo IV sobre los religiosos se creó una subcomisión ${ }^{[32]}$, 
la cual modificó el texto sustancialmente en relación con el esquema recibido de la Comisión Mixta; en el nuevo documento ya no se hablaba de los estados de perfección sino de la vocación a la santidad en general (Vaticano II, 1972, II/I, pp. 269-281). Estos esquemas fueron enviados a los Padres conciliares ${ }^{[33]}$.

La gestión de esta subcomisión fue sorprendente, pero también muy cuestionada, en especial por el procedimiento realizado, pues el esquema que se le entregó no retornó a ninguna Comisión y el nuevo esquema tampoco regresó a la reunión plenaria de la Comisión Doctrinal que la había creado, ni a la Comisión De Religiosis. Por el contario, el esquema final pasó directamente a la Comisión de Coordinación, quien discutió el capítulo IV bajo el título "De vocatione ad sanctitatem in Ecclesia" (Vaticano II, 1970, V/I, pp. 585-587 $)^{[34]}$ y dentro del cual se dedicaban cinco números a los religiosos: no. 32, De praxi consiliorum in statu vitae ab Ecclesia sancito; no. 33, De momento statuum perfectionis acquirendae in Ecclesia; no. 34, Sub auctoritate Ecclesiae; no. 35, Aestimanda est consecratio consiliorum evangelicorum y no. 36, Conclusio.

Es claro que los responsables de dicho esquema actuaron de manera contraria al procedimiento señalado para la aprobación de un documento conciliar; era ilícito que una pequeña subcomisión, como en este caso, tomara algunas decisiones directamente sin el parecer de las Comisiones a las que debía consultarse o desconociéndose opiniones manifestadas ${ }^{[35]}$.

El cambio del esquema del capítulo IV coincide con el pensamiento del cardenal Suenens, quien era miembro de la Comisión de Coordinación y relator ante la Comisión De Ecclessia. En su intervención durante la Sessio prima, Congregatio 3, del 23 de enero de 1963, ya había manifestado su opinión de no incluir el tema de los religiosos en un capítulo propio dentro de la Constitución De Ecclesia; también, en la Sessio secunda, Congregatio 4, del 28 de mayo, había dicho que los religiosos, al igual que los laicos, estaban llamados a la santidad y que los consagrados no gozan del hecho de ser superiores (Vaticano II, 1973, V/I, p. 463).

\section{Periodus Secunda}

El segundo periodo del Concilio fue del 29 de septiembre al 2 de diciembre de 1963. El Schema Constitutionis Dogmaticae De Ecclesia se discutió el 30 de septiembre en el aula de la Congregación General 37 (Vaticano II, 1972, II/I, pp. 215-281) ${ }^{[36]}$. Después de escuchar el parecer general y las animadversiones sobre el nuevo esquema, la Congregación General 38 consultó sobre su aprobación o desaprobación, obteniéndose el siguiente resultado (tabla 1):

TABLA 1.

Votación sobre la aprobación o desaprobación del esquema general de la Constitución Dogmática De Ecclesia

\begin{tabular}{|l|l|l|l|l|}
\hline $\begin{array}{l}\text { Praesentes } \\
\text { votantes }\end{array}$ & Placet & Non placet & $\begin{array}{l}\text { Placet iuxta } \\
\text { modum }\end{array}$ & Nulla \\
\hline 2301 & 2231 & 43 & 3 & 24 \\
\hline
\end{tabular}

Vaticano II (1972, II/I, p. 391)

Los votos positivos hacían suponer la acogida del esquema general, pero no se podían desconocer las objeciones hechas a lo largo de las sesiones siguientes ${ }^{[37]}$. Las reacciones hicieron que la Comisión de Coordinación elaborara un nuevo esquema ${ }^{[38]}$ que fue remitido a los Padres ${ }^{[39]}$, pero que no resultó acogido pues no tenía cambios significativos, por lo cual se mantuvo el esquema ya aprobado.

Algunos pedían un esquema nuevo debido a las supresiones notables y a las deficiencias profundas que el documento presentaba en comparación con el capítulo V del esquema de 1962. Sobre este punto, el cardenal Florit presentó un esquema nuevo en el que el tema de los religiosos tenía un capítulo propio y la vocación universal a la santidad debía ubicarse en otro lugar ${ }^{[40]}$. El cardenal Tabera Araoz presentó otra propuesta similar (Vaticano II, 1972, II/I, p. 742). Otros, en cambio, insistían que no se debía asignar un capítulo 
propio a los religiosos y que, además, el esquema del capítulo IV y de todo el documento De Ecclesia debía mantenerse ${ }^{[41]}$.

La reforma querida por algunos pedía separar el tema de la vocación a la santidad en la Iglesia, que aplicaba a todos los fieles, del tema de los estados de perfección, que aplicaba solo a un grupo de fieles. Ya que la santidad era una categoría aplicable a todos los miembros de la Iglesia, debía ubicarse como parte del capítulo referido al Pueblo de Dios y darle al tema de los religiosos un capítulo propio. Otra opción era darles parte de un capítulo sobre las categorías de las personas en la Iglesia en la que se tuviera en cuenta la identidad propia de los religiosos en la Iglesia (Vaticano II, 1972, II/III, pp. 196-198).

El capítulo IV sobre la vocación universal a la santidad se fundamentaba únicamente en la exhortación bíblica a ser perfectos como el Padre celestial (Vaticano II, 1972, II/I, p. 269, n. 29) (Mt. 5, 48), pero no mostraba el fundamento escriturístico-dogmático de la santidad cristiana, no se explicaba el argumento de la unión ontológica del cristiano con Cristo en la Iglesia ni el de la identificación permanente con él.

En cuanto al tema de los religiosos, tampoco se especificaba el tipo de unión con Cristo, lo que debe caracterizar este estado, ni se expresaban los elementos cristológicos y escatológicos que le son propios; tampoco se tenía en cuenta la doctrina definida por la Iglesia, proclamada por la tradición y el Magisterio acerca del valor de la consagración religiosa, que constituye el núcleo fundamental de la unión con Cristo; de igual forma, los votos religiosos tampoco estaban adecuadamente presentados. No se explicaba cómo la llamada a la santidad, común a todos los fieles, se especifica dentro de la vocación de cada persona a una determinada forma de vida ${ }^{[42]}$.

Las discusiones sobre una u otra posición no hacían olvidar a los más interesados la manera en la que había sido elaborado el capítulo IV. Esta situación fue admitida en el aula por el propio cardenal Döpfner, quien, actuando como miembro de la Comisión de Coordinación, en su intervención del 29 de octubre de 1963, a pesar de admitir la validez de dicho capítulo, reconoció la necesidad de enmendarlo en varios puntos (Vaticano II, 1972, II/III, p. 605), ya que en el capítulo De vocatione ad sanctitatem in Ecclesia, en general, no se describía con claridad la esencia de la vida religiosa y se requería que la doctrina sobre su valor y función en la Iglesia se presentara de modo más profundo.

Aunque las discusiones sobre el capítulo IV se desarrollaron en diversas Congregaciones Generales, en ellas también se discutieron otros temas ${ }^{[43]}$; por esta razón es propio asegurar que el capítulo IV De vocatione ad sanctitatem in Ecclesia no fue plenamente discutido. Objetivamente, este fue el espacio dado a la discusión de dicho capítulo en el aula conciliar ${ }^{[44]}$. Aunque solo se concedieron algunas intervenciones orales, y se recibieron los pareceres escritos de los Padres, se constató la existencia de posiciones diversas frente al esquema. A pesar de que no habían podido intervenir todos los que lo habían pedido para expresar su parecer ${ }^{[45]}$, el iter del documento debía seguir adelante, lo que dejaba en punta su discusión.

Ante las dificultades que surgieron para debatir el capítulo IV, se buscaron caminos de solución ${ }^{[46]}$, por esto, y de manera paralela y no oficial, se creó un grupo defensor de tal documento. Algunos autores reconocen aciertos en la gestión de dicho grupo ${ }^{[47]}$, mientras que otros no ven con claridad tales aportes ${ }^{[48]}$.

\section{Periodus Tertia}

Ante la situación generada en torno al capítulo IV se consideró necesario revisarlo, para lo que se creó una subcomisión formada por miembros de la Comisión de Coordinación, De Religiosis. De Fide, la cual presentó un nuevo esquema que fue revisado y aprobado por la Comisión De Fide et Moribus luego de hacerle algunas correcciones (Vaticano II, 1976, III/I, pp. 322-329).

La subcomisión consideró el hecho de que un grupo de Padres aprobara el esquema del capítulo IV, pero otro grupo de 679 Padres pidiera su revisión y modificación. Esta subcomisión se preguntó, además, si el capítulo IV se debía mantener como estaba o si mejor debía ser dividido de tal modo que los números sobre 
la vocación universal fueran enviados a otro lugar y así se le diera al tema de los religiosos un capítulo propio. Discutida esta situación se consideró que, por lo menos, debía decirse algo sobre la santidad universal en el capítulo que trataba del Pueblo de Dios y tratar el tema de manera más profunda en otro lugar del documento; además, este debía distinguir el tema de la vocación universal a la santidad del tema de los religiosos.

No todos estaban de acuerdo con que a estos dos temas debían hacérseles dos capítulos separados o un mismo capítulo con dos secciones referidas a la vocación universal a la santidad y a los religiosos. Tal tarea fue dejada a la Comisión Doctrinal Plenaria, quien delegó este encargo a una Comisión Mixta Plenaria que tampoco abordó el tema.

El documento fue enviado a la Comisión de Coordinación y luego a la Comisión Doctrinal (Vaticano II, 1973, V/II, pp. 185, 558-559), la cual aprobó un texto nuevo, pero manteniendo la duda sobre tratar el tema De vocatione ad sanctitatem como un capítulo con dos secciones o dividido en dos capítulos, uno de los cuales trataría a De Religiosis (Vaticano II, 1973, V/II, pp. 183-184) ${ }^{[49]}$.

El 3 de julio de 1964, el Santo Padre ordenó enviar el nuevo documento a los Padres conciliares, este contaba con ocho capítulos para que se considerara uno para De Religiosis o siete capítulos si se dejaba una sección dentro de un capítulo para que tratara tanto la vocación a la santidad como a los religiosos.

En la elaboración del nuevo documento tuvo efecto la intervención del Papa Pablo VI, realizada el 23 de mayo a un grupo de religiosos; en esta reconocía, entre otros puntos, la importancia de la vida religiosa en la Iglesia, el valor de los consejos evangélicos, la disciplina que le es propia, su adaptación y renovación, su vida espiritual, el apostolado y su relación con la Jerarquía (Pablo VI, 1964). El discurso animó al grupo, deseoso de aprobar un texto, a que se diera a los religiosos un capítulo propio (Vaticano II, 1976, III/VI, p. 119) ${ }^{[50]}$, por lo que exhortaron a los Padres conciliares a escribir, muchos de los cuales acogieron este llamado.

El 15 de septiembre, en la Sessio Tertia, se discutió el nuevo esquema de la Constitución De Ecclesia (Vaticano II, 1976, III/I, pp. 158-375) ${ }^{[51]}$ que trataba el tema de los religiosos ${ }^{[52]}$. Sugeridas algunas enmiendas a este tema (Vaticano II, 1976, III/III, pp. 65-68), se interrogó si debía votarse como un capítulo propio o como sección de un capítulo junto al tema de la vocación a la santidad (Vaticano II, 1976, III/I, pp. 395-396). La Congregación General 91, del 30 de septiembre de 1964, mostró de modo absolutamente claro que el tema De Religiosis debía tener un capítulo propio en la nueva Constitución (tabla 2):

TABLA 2.

Resultados de la votación para incluir el tema De Religiosis como capítulo en la Constitución

\begin{tabular}{|l|l|l|l|l|}
\hline Inter Patres & Placet & Non placet & $\begin{array}{l}\text { Placet iuxta } \\
\text { modum }\end{array}$ & Nulla \\
\hline 2210 & 1505 & 698 & 4 & 3 \\
\hline
\end{tabular}

Vaticano II (1976, III/I, pp. 395-396)

El contenido del capítulo VI De Religiosis se votó en la misma Congregación General y alcanzó el siguiente resultado (tabla 3):

TABLA 3.

Resultados de la votación sobre el capítulo IV del tema De Religiosis

\begin{tabular}{|l|l|l|l|l|}
\hline $\begin{array}{l}\text { Praesentes } \\
\text { votantes }\end{array}$ & Placet & Non placet & $\begin{array}{l}\text { Placet iuxta } \\
\text { modum }\end{array}$ & Nulla \\
\hline 2189 & 1736 & 12 & 438 & 3 \\
\hline
\end{tabular}

Vaticano II (1976, III/VIII, p. 127)

Una vez se definió el contenido, se procedió a enmendarlo (Vaticano II, 1976, III/VIII, pp. 127-137); se sometió de nuevo a votación del aula en la Congregación General 125, el 18 de noviembre, y logró el siguiente resultado (tabla 4): 
TABLA 4.

Votación sobre la enmienda al contenido del tema De Religiosis

\begin{tabular}{|l|l|l|l|l|}
\hline $\begin{array}{l}\text { Praesentes } \\
\text { votantes }\end{array}$ & Placet & Non placet & $\begin{array}{l}\text { Placet iuxta } \\
\text { modum }\end{array}$ & Nulla \\
\hline 2131 & 2114 & 12 & 4 & 1 \\
\hline
\end{tabular}

Vaticano II (1976, III/VIII, p. 363)

Durante la Congregación General 126, del 19 de noviembre, se puso en consideración el esquema general de la Constitución Dogmática De Ecclesia y luego de ser votada dio el siguiente resultado (tabla 5):

TABLA 5.

Votación sobre el esquema general de la Constitución Dogmática De Ecclesia

\begin{tabular}{|l|l|l|c|}
\hline $\begin{array}{l}\text { Praesentes } \\
\text { votantes }\end{array}$ & Placet & Non placet & Nulla \\
\hline 2145 & 2134 & 10 & 1 \\
\hline \multicolumn{3}{c}{ Vaticano II (1976, III/VIII, p. 407) }
\end{tabular}

Fuente: Vaticano II (1976, III/VIII, p. 407)

En la Sessio Publica 5. a del 21 de noviembre de 1964, fue puesto el tema a votación definitiva y dio como resultado 2151 placet contra 5 non placet. El Santo Padre Pablo VI aprobó y proclamó la Constitutio Dogmatica Lumen Gentium (Vaticano II, 1976, III/VIII, pp. 780-783); esta tenía 8 capítulos $^{[53]}$, el capítulo VI trataba De Religiosis ${ }^{[54]}$, era más extenso y rico en contenido, y contaba con mayor profundidad teológica, eclesiológica y pastoral al tratar la vida religiosa.

\section{Elementos presentes en el capítulo VI de Lumen Gentium:}

Al estudiar y analizar el iter del capítulo VI de Lumen Gentium sobre la vida religiosa se constata su importancia dentro del documento total. No se pueden ignorar los conflictos habidos durante el Concilio en torno a la elaboración de dicho texto, especialmente si se tiene en cuenta que hubo una fuerte corriente que proponía no considerar la vida religiosa como un elemento constitucional de la Iglesia (Ghirlanda, 1977, p. 82). Al final se logró un documento sólido y denso que presenta esta forma de ser en la Iglesia con los elementos que la caracterizan y que deben estar presentes en todas sus acciones. Ahora trataremos de reconocer dichos elementos $^{[55]}$.

\section{Consejos evangélicos: don de Dios}

En el Lumen Gentium 43a se expresa que los consejos evangélicos de castidad consagrada a Dios, de pobreza y de obediencia, como fundados en las palabras y ejemplos del Señor, y recomendados por los Apóstoles y Padres, así como por los doctores y pastores de la Iglesia, son un don divino que la Iglesia recibió del Señor y que con su gracia conserva siempre.

La vida religiosa tiene relación directa con Dios, que es su causa y origen. "Es esencialmente un don especial hecho al Cuerpo Místico de Cristo [...] para el enriquecimiento de la vida de la Iglesia misma” (Gambari, 1966b, p. 299; traducción propia ${ }^{[56]}$. Este don es prueba del amor que Dios tiene por la Iglesia y se manifiesta dándole un estado de vida predilecto en su corazón (Gambari, 1966b, p. 307; traducción propia) ${ }^{[57]}$. Es Dios quien toma la iniciativa de dar este don a la Iglesia; así, su carácter teológico se concretiza en la profesión de los consejos evangélicos, los cuales son una vivencia de castidad, pobreza y obediencia por el reino de los cielos (Fagiolo, 1988, p. 9) que, asumidos como realidad escatológica, son un don de Dios para la Iglesia.

Los consejos tienen a Cristo como centro, cuyas enseñanzas no son una mera doctrina sino una actitud de vida aceptada por Él para actualizar la voluntad del Padre (Beyer, 1975, p. 52), de ahí su vida casta, pobre 
y obediente hasta la muerte en cruz. Los consejos colaboran en la instauración del plan salvífico a fin de reconciliar todas las cosas con el Padre, incorporan a quienes los profesan a un particular estado en la Iglesia, son un signo escatológico de la vida de Cristo y de la manifestación del Reino de Dios en la vida presente (Molinari y Gumpel, 1985, p. 199); por esto los consejos son un don para la Iglesia y ella los ha recibido de su Señor y con su gracia los conserva siempre (Vaticano II, 1964, 43a) a fin de seguirlo más de cerca ${ }^{[58]}$.

\section{Consejos evangélicos: respuesta del hombre}

\section{En Lumen Gentium 44a se lee:}

El cristiano, mediante los votos u otros vínculos sagrados - por su propia naturaleza semejantes a los votos- con los cuales se obliga a la práctica de los tres consejos evangélicos, hace una consagración total de sí mismo a Dios, amado sobre todas las cosas, de manera que se ordena al servicio de Dios y a su gloria por un título nuevo y especial.

Si los consejos evangélicos son un don de Dios que se comunican en la llamada que Él hace al hombre, entonces, en segundo lugar, se da la respuesta amorosa, libre y personal a Dios como donación total de sí mismo, el cual es amado sobre todas las cosas a fin de hacerlo el único Bien; él es la donación que abraza toda la vida y exige el ofrecimiento definitivo de todo cuanto se tiene: corazón y sentimientos (Vaticano II, 1964, 42-43, 1965a, 12), los bienes externos y la propia voluntad (Vaticano II, 1965b, 14), lo cual se asume como obligación libremente aceptada. Tal obligatoriedad, asumida con la profesión, es un elemento constitutivo para la observancia de dichos consejos ${ }^{[59]}$. La respuesta del hombre no es posible sino en Jesucristo, por él, con él y como él. Esta se hace normalmente en la Eucaristía y se hace de manera definitiva, aunque los vínculos sean temporales ${ }^{[60]}$.

La fuerza de la consagración reside en el don del amor recibido de Dios y al cual responde el amor que se manifiesta en la aceptación de la elección divina por parte de quien se consagra a él definitivamente. Esta donación, sellada con los votos, conduce a una configuración con Cristo y, en cierto modo, a una reproducción de toda su vida y misión (Sericoli, 1966, p. 486) ${ }^{[61]}$, y a un compartir más estrecho con la obra del Redentor que por su castidad, pobreza y obediencia hasta la muerte ha querido redimirnos y santificarnos.

$\mathrm{Al}$ reconocer la importancia del amor en el acto de donación la profesión de los consejos evangélicos se constituye en una condición especial, pues estos están referidos a un estado de vida ${ }^{[62]}$, por lo cual "no son solo simples consejos, sino que por libre elección se convierten 'in formam praecepti" "63] que deben ser fielmente observados a fin de ofrecerse más y totalmente al Padre en Cristo, con la ayuda del Espíritu Santo, viviendo para Él y siguiéndolo como única realidad necesaria ${ }^{[64]}$. "[...] aquel que se consagra a Dios, puede hacerlo tan solo porque Dios lo ha elegido para sí, lo ha consagrado para sí” ${ }^{\text {[65] }}$. No es el cristiano quien primero se consagra a Dios, es Él quien llama a su servicio a vivir una consagración más plena, íntima y profunda. Sobre este aspecto, Lumen Gentium 44 a enseña:

Ya por el bautismo había muerto al pecado y estaba consagrado a Dios; sin embargo, para traer de la gracia bautismal fruto más copioso, pretende, por la profesión de los consejos evangélicos, liberarse de los impedimentos que podrán apartarle del fervor de la caridad y de la perfección del culto divino, y se consagra más íntimamente al servicio de Dios. La consagración será más perfecta cuanto, por vínculos más firmes y más estables, represente mejor a Cristo, unido con vínculo indisoluble en su Iglesia.

En ese sentido, si

en el acto del bautismo Dios puso su mano sobre nosotros, nos consagró y nos unió a su vida, toda la vida cristiana no es otra cosa que la respuesta a esa llamada fundamental, a esa primera elección de Dios. La nueva consagración se inserta en la consagración bautismal ${ }^{[66]}$ 
Aquella es una consagración especial y más radical para actualizar continuamente la santidad propia de este estado de vida (Vaticano II, 1964, 46a-47), que hunde sus raíces en la consagración bautismal, la cual sumerge al fiel en el misterio pascual de su muerte y resurrección (Beyer, 1975, pp. 748-749) ${ }^{[67]}$.

Si por el bautismo nace la consagración del cristiano a Dios, de esta consagración genérica y común, junto con la profesión de los consejos evangélicos, se da paso a una consagración especial que no solo consagra el fiel a Dios con un título nuevo y especial, sino que, además, de frente a la Iglesia, lo hace asumir la tarea de liberarse de los impedimentos que podrían alejarlo del favor de la caridad y de la perfección del culto divino, para consagrarse más íntimamente al servicio de Dios (Pablo VI, 1964).

Si con el bautismo el cristiano muere al pecado, es consagrado a Dios y es llamado a la santidad (Vaticano II, 1964, 44a), con la profesión de los consejos evangélicos se renuncia al mundo y se vive únicamente para Dios (Vaticano II, 1965b, 5); de esta forma, se busca obtener frutos más copiosos y así liberarse de los impedimentos que pueden destruir el fervor de la caridad (Vaticano II, 1964, 44a). La nueva consagración busca una entrega plena a Dios, una opción radical de la gracia bautismal y una asimilación mayor con Cristo (Galot, 1978, pp. 590-592).

Esta consagración invita a entrar más conscientemente dentro de la vida de Dios (Beyer, 1975, p. 639), a generar una unión escatológica con Dios a través de Cristo (Schulte, 1968, p. 1082) y a una relación más profunda con la Iglesia (Beyer, 1966, p. 39) en la que el seguidor de Cristo debe intentar alcanzar la plenitud de su consagración a Dios con la observancia de los consejos evangélicos y la forma estable de una vida orientada a conseguir la perfección de la caridad ${ }^{[68]}$; y, para ello, el seguidor cuenta con la ayuda de todos los miembros de la Iglesia, donde vive su compromiso de manera pública ${ }^{[69]}$. Por consiguiente,

el vínculo con la Iglesia es mucho más estrecho y su acción es indispensable cuando la consagración asume la forma de estado o de institución en la Iglesia misma [...]. Es la Iglesia, que en unión al Señor y como instrumento de la acción divina, confiere esta consagración”. (Gambari, 1966b, p. 304; traducción propia) ${ }^{[70]}$

La consagración exige que se ame a Dios, quien nos amó primero (Vaticano II, 1965b, 6a), que se viva sólo para Él (Vaticano II, 1965b, 5a) y que en toda ocasión se procure con afán fomentar la vida escondida con Cristo en Dios (Vaticano II, 1965b, 6a), para lo que es necesario cultivar con asiduidad el espíritu de oración y la oración misma. "En efecto, aquellos que se obligan a dicho modo de vivir según los consejos evangélicos no retienen absolutamente nada para sí, sino que son dados a Dios en todo cuanto ellos son y tienen" (Molinari y Gumpel, 1985, p. 191; traducción propia) ${ }^{[71]}$.

\section{Eclesialidad de la vida religiosa}

Lumen Gentium, en el capítulo VI, ofrece otros elementos importantes. En primer lugar, en cuanto a la eclesialidad de los consejos evangélicos, indica que "la consagración [...] a Cristo en la Iglesia es para el bien de la Iglesia” (Molinari y Gumpel, 1985, p. 209; traducción propia) ${ }^{[72]}$; y, al respecto, en el no. 44 b dispone:

Pero como los consejos evangélicos, mediante la caridad hacia la que impulsan, unen especialmente con la Iglesia y con su ministerio a quienes los practican, es necesario que la vida espiritual de estos se consagre también al provecho de toda la Iglesia [...]. Por consiguiente, el estado constituido por la profesión de los consejos evangélicos, aunque no pertenece a la estructura jerárquica de la Iglesia, pertenece, sin embargo, de manera indiscutible, a su vida y santidad.

"La vida religiosa se presenta como la proyección de la Iglesia; es, por lo tanto, solo en el seno de la Iglesia y a la luz de la Iglesia que ella se puede conocer" (Gambari, 1966a, p. 34; traducción propia) ${ }^{[73]}$, pues pertenece a la Iglesia y a su ministerio de una especial manera. Aunque no pertenece a su estructura jerárquica, pertenece, de manera indiscutible, a su vida y santidad, como lo expresa Lumen Gentium $44 \mathrm{~d}^{[74]}$. Esta afirmación determina la manera de ser de la vida consagrada en la Iglesia. 
La vida religiosa hace parte de la estructura de la Iglesia en razón del fin mismo de la Iglesia que es la santidad: ella hace parte de la Iglesia sea como expresión de santidad, sea como medio o instrumento de santificación [...]. (Gambari, 1966b, p. 304; traducción propia) ${ }^{[75]}$

Por lo tanto, por tener una identidad totalmente eclesial, la vida religiosa actúa en nombre de la Iglesia, es su representante y cumple con la tarea particular de expresar de manera especial su santidad; así, ella, que nace en. para la Iglesia, se constituye y es reconocida como un Estado. Si la vida de la Iglesia está determinada por la misión salvífica de Cristo y al mismo tiempo desarrolla su misión porque es santificada por Cristo (Ghirlanda, 1984, p. 80), entonces la vida religiosa, por pertenecer a la Iglesia, asume de manera radical esta tarea.

\section{Carismas en la vida religiosa}

Como ya se dijo, "el carácter eclesial de la vida consagrada es fundado sobre el bautismo y se vive en la Eucaristía” (Beyer, 1975, p. 749; traducción propia) ${ }^{[76]}$. Dicho carácter se comunica a cada Instituto Religioso en la Iglesia, lo que los lleva a asumir deberes y tareas particulares para vivir un servicio a Dios y una dedicación a la Iglesia entera (Vaticano II, 1965b, 1c, 6a), en la que su vida apostólica, activa o contemplativa, vivida al interior de la Iglesia y como expresión de su santidad, los une a ella en la totalidad de su ministerio y les permite desarrollar las tareas que le son propias según el carisma particular de cada Instituto (Gambari, 1970, p. 105).

Del amor generoso de Dios brotan muchos carismas, cada uno es un don con una particular inspiración y tarea en la Iglesia. Al respecto Lumen Gentium 43a enseña:

Esta es la causa de que, como en árbol que se ramifica espléndido y pujante en el campo del Señor partiendo de una semilla puesta por Dios, se hayan desarrollado formas diversas de vida solitaria o comunitaria y variedad de familias que acrecientan los recursos ya para provecho de sus propios medios, ya para el bien de todo el Cuerpo de Cristo.

Los carismas dados por Dios a los fundadores de los institutos religiosos son un regalo para la Iglesia que vive internamente el misterio de comunión; estos constituyen una parte importante en su vida y de su estructura neumática (Gambari, 1970, p. 105). Gracias a su variedad, la Iglesia puede presentar múltiples aspectos de la vida y misión de Cristo (Vaticano II, 1964, 46). Cada carisma particular determinará la manera de vivir los consejos evangélicos dentro de la comunión eclesial con todo lo que ella es, exige y significa; en ese sentido, tales carismas se muestran como un modo de vida propio a través del cual se desarrolla toda la eclesialidad de la vida religiosa (Gambari, 1966a , p. 35). Por tanto, lejos de concebir la vida religiosa como algo paralelo a la vida de la Iglesia, o algo que se desarrolla bajo su mirada benigna o bajo su control, ella debe ser vista en todas sus manifestaciones, es decir, como una vida íntimamente ligada a la vida de la Iglesia, como expresión de su vitalidad y fecundidad, pues la vida religiosa hace parte de la estructura de la Iglesia en razón del fin mismo de la Iglesia que es la Iglesia (Gambari, 1966b, p. 304).

\section{Autoridad en la Iglesia}

La Iglesia, en el ejercicio de autoridad que le fue conferido por su Fundador y bajo la guía del Espíritu Santo, se preocupa por interpretar los consejos evangélicos que recibe y establece medios para regular su práctica, por lo que llega incluso a determinar maneras de vivirlos (Vaticano II, 1964, 43a). Así, se reconocen formas diversas de familias religiosas que surgen para el bien de todo el Cuerpo Místico de Cristo que viven un don particular y con el cual contribuyen a la misión salvífica de la Iglesia. La Iglesia reconoce estos dones y los hace fructificar; con lo que no solo la embellecen sino que se interesa por ellos y los cuida para que den fruto ${ }^{[77]}$.

Sobre este punto Lumen Gentium 45 señala que:

Siendo deber de la Jerarquía eclesiástica apacentar al Pueblo de Dios y conducirlo a los mejores pastos (Ez. 34, 14), a ella compete dirigir sabiamente con sus leyes la práctica de los consejos evangélicos, mediante los cuales se fomenta singularmente 
la caridad para con Dios y para con el prójimo. La misma Jerarquía, siguiendo dócilmente los impulsos del Espíritu Santo, admite las reglas propuestas por varones y mujeres ilustres, las aprueba auténticamente después de haberlas revisado y asiste con su autoridad vigilante y protectora a los Institutos erigidos por todas partes para edificación del Cuerpo de Cristo, con el fin de que en todo caso crezcan y florezcan según el espíritu de los fundadores [...]. La Iglesia no solo eleva mediante su sanción la profesión religiosa a la dignidad de estado canónico, sino que, además, con su acción litúrgica, la presenta como un estado consagrado a Dios. Ya que la Iglesia misma, con la autoridad que Dios le confió, recibe los votos de quienes profesan, les alcanza de Dios, mediante su oración publica, los auxilios y la gracia, los encomienda a Dios y les imparte la bendición espiritual, asociando su oblación al sacrificio eucarístico.

Si los consejos evangélicos unen a quienes los viven (Vaticano II, 1964, 44b), especialmente con la Iglesia y con su ministerio, esta tiene la tarea no solo de acoger y aprobar el don de Dios, sino también de orientarlo.

Beyer (1975) argumenta que "si el don hecho a un fundador debe ser acogido, aprobado y protegido, esta responsabilidad no incumbe tal solo al Instituto: es una responsabilidad eclesial, que hace referencia a todos los fieles, y de manera especial a la jerarquía" (p. 750; traducción propia) ${ }^{[78]}$, la cual no tiene la tarea de crear nuevos Institutos, propiamente hablando, sino que, siguiendo dócilmente el impulso del Espíritu Santo, que es quien los crea, acepta las reglas propuestas para acoger una nueva forma de vida religiosa. Igualmente, el fundador admite los carismas, los aprueba auténticamente y los asiste con su autoridad vigilante y protectora para la edificación del Cuerpo de Cristo (Vaticano II, 1964, 45a), permitiendo así que este don, comunicado por el Espíritu Santo, se concrete al interior de la Iglesia, estableciéndose una comunión eclesial de la cual la jerarquía es garantía de autenticidad ${ }^{[79]}$.

Sobre este aspecto Sugawara comenta:

La naturaleza específica de cada Instituto está determinada y constituida por sus fundadores y es aprobada por el deseo positivo de la Iglesia a través de su jerarquía institucionalmente constituida. La jerarquía no crea el estado de vida consagrada, pero lo hace presente y ofrece a Dios en nombre de la Iglesia. La consagración de este estado no existe porque es aprobado, sino que es aprobado porque existe en la Iglesia como un regalo del Espíritu Santo. El carisma es dado por iniciativa divina; la aprobación por la autoridad eclesiástica es un reconocimiento de su autenticidad. (Sugawara, 1997, p. 53-54; traducción original) ${ }^{[80]}$

En relación con la institucionalidad del carisma, G. Ghirlanda comenta que el carisma colectivo llega a ser un Instituto canónico en el momento en el que la Iglesia reconoce su utilidad y, por consiguiente, lo aprueba. Tal aprobación, hecha por aquellos que tienen el carisma-ministerio de discernir todos los carismas, debe hacerse a fin de que todo coopere al bien de la Iglesia, protegiendo el don que Cristo ha querido comunicarle mediante la profesión de los consejos evangélicos, y manteniendo vivo el don que el Espíritu suscita y da en cada uno de los carismas particulares (Ghirlanda, 1992, p. 474; traducción propia) ${ }^{[81]}$.

En consecuencia, es necesario concluir que se da una relación de doble vía: por una parte, la jerarquía debe dirigir sabiamente con sus leyes la práctica de los consejos evangélicos a fin de ayudar a cuantos los profesan a alcanzar la perfección de la caridad para con Dios y para con el prójimo (Vaticano II, 1964, 45a), para lo que debe tener presente tutelar el espíritu de los fundadores para la edificación del Cuerpo de Cristo.

Por otra parte, la respuesta de los Institutos aprobados por la jerarquía eclesial reclama, en fidelidad al don de Dios, una identidad con la Iglesia Universal que los acoge en cabeza del Romano Pontífice y con las iglesias particulares orientadas por los obispos (Vaticano II, 1964, 45b), con quienes en comunión, según el carisma particular, deben ser símbolo eficaz del Cuerpo Místico de Cristo a quien siguen y sirven en la construcción del Reino ${ }^{[82]}$.

\section{Conclusiones}

Al concluir este artículo se hace necesario reconocer la importancia y relevancia canónica del capítulo VI de la Constitución Dogmática Lumen Gentium del Concilio Vaticano II. 
En primer lugar, en cuanto a su proceso de elaboración histórica, luego de no pocas discusiones en cuanto a su contenido, en el texto final se evidencian elementos y principios doctrinales presentes y tenidos en cuenta al momento de elaborarse las normas de la legislación canónica en cuanto a la administración y enajenación de bienes temporales de institutos religiosos.

Tales elementos se constituyeron en directrices que debían ser tenidas en cuenta no solo a la hora de elaborar el código actual, sino también en las acciones concretas de administración y enajenación realizadas por cada Instituto Religioso a la luz de las exigencias de la Iglesia y del derecho propio (Cenalmor y Miras, 2004, p. 83).

En segundo lugar, del estudio de Lumen Gentium capítulo VI se concluye que, aunque estrictamente hablando dicho documento no hace un estudio jurídico amplio y detallado de la administración y enajenación de bienes temporales de institutos religiosos, no se puede desconocer que su sentido y alcance se tuvo en cuenta y constituyó el trasfondo de la ley canónica.

Si bien se constata que Lumen Gentium capítulo VI no trata la administración y enajenación de bienes de institutos religiosos, el texto no puede leerse buscando únicamente una presentación legalista de dicho tema, sino que debe leerse con una mirada más abierta que sea capaz de encontrar en él elementos referidos al hecho de considerar la vida religiosa como un don de Dios que espera una respuesta del hombre. Sin embargo, esta experiencia es vivida en la Iglesia, a la luz de un carisma propio y bajo la autoridad eclesiástica competente, elementos que ayudan a la mayor y mejor comprensión de lo que implica y significa la vida religiosa, y elementos también aplicables a la administración y la enajenación.

Si la administración y la enajenación de bienes no se mencionan de manera explícita en Lumen Gentium capítulo VI, ello no significa que se esté desconociendo su existencia en la Iglesia, a fin de cuentas, esta Constitución Dogmática no pretendía dar normas jurídicas sobre temas de naturaleza económica eclesial y religiosa. Una hermenéutica más amplia permite confirmar que los elementos de la vida religiosa presentes en el texto, que dan una identidad a esta forma de ser en la Iglesia, la cual se refleja en todos sus actos, también inciden en la administración y en la enajenación de bienes.

Si con el tema de la administración de bienes la mención no es explicita, sino que tiene que descubrirse entre líneas en este texto conciliar, la cosa resulta menos evidente en el caso de la enajenación, pues, aunque formaba parte de algunos de los postulados presentados en los orígenes del Concilio, su alusión pronto desapareció.

Tal situación no debe ser entendida como una abolición del tema, sino que debe ser incluida como parte del tema económico general de la administracióndentro del que se deben incluir otras acciones que también se adelantan sobre los bienes. Para su comprensión específica debe acudirse al CIC (Juan Pablo II, 1983) que ciertamente hace alusión tanto a la administración como a la enajenación de bienes, al igual que al derecho propio de cada Instituto.

A pesar de la generalidad del texto conciliar, este ofrece argumentos que iluminan la acción económica de la administración y enajenación de bienes de institutos religiosos.

En tercer lugar, en este documento conciliar también se deben reconocer las características particulares que identifican la vida religiosa y que tienen incidencia en el tema de la administración y la enajenación de bienes temporales.

Los institutos religiosos deben ser una realidad contratante en medio del mundo, los testigos y el testimonio de la santidad eclesial, que es el camino permanente hacia la plenitud de la vida en Dios en medio de las tensiones presentes; así, esta manera de ser reclama una forma diferente de estar en el mundo sin ser de él, es una forma de relacionarse con todo lo que existe, manteniendo su mirada trascendente en el fin mayor que le corresponde. Pero la forma de ser de estos Institutos también debe estar presente al momento de administrar o enajenar bienes eclesiásticos, los cuales, al pertenecer a estas personas jurídicas públicas, deben ser atendidos a la luz de la identidad que a tales personas jurídicas corresponde en la Iglesia.

De lo dicho surgen ciertos elementos que deben ser aplicados o tenidos en cuenta al momento de adelantar acciones jurídicas por parte de los Institutos, dentro de las cuales se ubican la administración y la enajenación 
de bienes temporales, características necesarias para que estos avancen hacia el fin mayor al que están llamados en la Iglesia.

Por lo tanto, la identidad propia de la vida religiosa determina también los actos de administrar y enajenar bienes, sus elementos no son ajenos, sino que inciden y están presentes en tales actos; por esta razón, es a través de tales acciones que la vida religiosa explicita su ser en la Iglesia.

En cuarto lugar, si la legislación Pío-Benedictina había presentado una reglamentación sobre la administración y enajenación de bienes de institutos religiosos (Juan Pablo II, 1983, 17, cc. 531-537) marcada por una fuerte línea jurídica positiva, en ocasiones rigurosa y extrema; ahora Lumen Gentium capítulo VI ofrece fundamentos que dan un significado nuevo al sentido universal de los bienes, a su origen y a su finalidad, así como a los aspectos teológico, eclesiológico y pastoral, pues estos enriquecen los elementos jurídicos de la legislación canónica actual (Juan Pablo II, 1983, cc. 634-640) aplicables a los bienes de los institutos religiosos que, a su vez, determinan o inciden en su administración o enajenación.

En cuanto al fundamento universal de los bienes temporales cabe agregar que participan del sentido universal, valor y uso que la doctrina del Concilio Vaticano II les reconoce en su relación con la sociedad humana. Al respecto, Gaudium et Spes señala que

Dios ha destinado la tierra y cuanto ella contiene para uso de los hombres y de los pueblos, en consecuencia, los bienes creados deben llegar a todos [...]. Sean las que sean las formas de propiedad, adaptadas a las instituciones legítimas de los pueblos según las circunstancias diversas y variables, jamás debe perderse de vista este destino universal de los bienes. (1965a, 69a)

Los bienes creados tienen una razón y ordenación divina, real y objetiva, ellos tienen un valor justo y un recto uso, de lo cual nadie en la sociedad humana o en la eclesiástica puede racionalmente sustraerse. El Concilio reconoce explícitamente la existencia de tal ordenación divina cuando afirma que "los bienes creados, de acuerdo con el designio del Creador y la iluminación de su Verbo, [son] promovidos” (Vaticano II, 1964, 36b).

En cuanto al origen y el fin de los bienes, el Concilio señala que, en relación con el origen divino de los bienes creados, Dios, que creó todas las cosas, es también Creador de los bienes temporales, los cuales gozan de la condición positiva de ser bienes y por tanto de ser buenos, así como del hecho de ser dones de Dios, por lo que deben ser estimados y cultivados. Al respecto, Gen. 1, 31, recuerda que: "Vio Dios cuanto había hecho, y todo estaba muy bien".

En cuanto al fin último, los bienes temporales deben estar encaminados hacia Dios, quien, como todo lo ha hecho para sí, también somete bajo esta condición los bienes temporales, los cuales, creados por Él, a Él deben volver: "Porque es un deber y un honor para el cristiano devolver a Dios parte de los bienes que de Él recibe" $(A A, 10 \mathrm{c})$. El fin último determina el fin inmediato al que se destinan dichos bienes.

En cuanto al fundamento teológico de los bienes, y siguiendo el ejemplo de Cristo, que siendo rico se hizo pobre (2 Cor. 8-9), los Institutos, en la Iglesia, deberán vivir ese mismo espíritu de pobreza. Eso supone, desde el punto de vista ascético, el desprendimiento de los bienes materiales, ya que tales bienes solo han de utilizarse como medios para realizar los fines que corresponden a la misión encomendada a la Iglesia por Jesús (Schouppe, 2007, p. 30).

Partiendo de dicha premisa, el Concilio ratifica la identidad propia de la Iglesia, la cual debe reflejarse en todos sus campos, incluido el campo económico y patrimonial. En este sentido, y teniendo de base el espíritu de pobreza, el uso de los bienes temporales tienen su justificación y su medida en relación al cumplimiento de la misión de la Iglesia, derecho que esta ejerce de manera libre e independiente (Vaticano II, 1965a, 76; Pablo VI, 1965) a fin de poder llevar adelante su tarea; además, con el uso de tales bienes manifiesta la caridad, el desprendimiento y la generosidad a la luz del Evangelio, y no el deseo de acumulación de bienes y de riqueza (Vaticano II, 1965b, 13).

Los bienes temporales se convierten así en medios o elementos de ayuda que posibilitan la tarea de la Iglesia de testimoniar la vida nueva y eterna conquistada por la redención de Cristo, la prefiguración de la futura 
resurrección y la gloria del reino celestial (Vaticano II, 1964, 44c); sin embargo, estos bienes no solo deben ser adquiridos sino también administrados para estos fines, administración que aunque deba ajustarse a las exigencias legales, debe tener un sentido jurídico, positivo y pastoral especial.

Una Iglesia que no rechaza los bienes temporales ni los más modernos medios de progreso, pero que no olvida su misión, sino que a ella tiende, teniendo siempre una opción por la pobreza, da a la administración de los bienes un valor y un sentido nuevo (Bettazzi, 1968, pp. 969-972).

Los bienes temporales tienen unos fines inmediatos reconocidos por el Concilio. Si los bienes eclesiásticos en general se destinan "para la ordenación del culto divino, para procurar la honesta sustentación del clero y para ejercer las obras del sagrado apostolado o de caridad, señaladamente con los menesterosos" (Juan Pablo II, 1983 , c. 1254, \$2), entonces tales fines marcan un horizonte que debe ser atendido también por los institutos religiosos, quienes deben dedicar sus bienes "para la vida temporal y para sus obras" (Vaticano II, 1965b, 13), con lo cual se entiende la honesta sustentación de sus miembros, las obras de apostolado y de caridad como en favor del culto divino. Será el carisma de cada Instituto el que determine el uso de los bienes, siempre y cuando atienda al fin que les es propio.

El fin mayor al que se destinan los bienes de los Institutos limita el derecho a poseerlos, pues ellos no se adquieren con intenciones económicas ordenadas solo a los fines temporales o económicos ni con el deseo de atesorar riquezas, ni de aferrarse a las cosas terrenas, sino que, por el contrario, son una ayuda en la tarea de avanzar hacia la consumación de todo lo existente en Cristo, en la que la adquisición de bienes temporales tiene un sentido (Gambari, 1971, pp. 79-81) y un valor apostólico pues ayudan en la tarea salvadora de humanidad.

La administración de bienes debe estar íntimamente ligada con el estilo de vida pobre y austero propio de cada Instituto; por tal motivo, es igualmente importante determinar el estilo que debe caracterizar dicha administración a la que le compete no solo asegurar el desarrollo y la expansión de la misión del Instituto y el bienestar de sus miembros, sino favorecer de la mejor manera que la vida en la pobreza que cualifica a los Institutos y a sus consagrados en el seguimiento de Jesucristo (Arenas y Torres, 2006, p. 11) ${ }^{[83]}$.

En relación con el fundamento eclesiológico de los bienes, el Concilio confirmó que la Iglesia, como realidad que actúa en el mundo, necesita de los bienes materiales para cumplir su misión, pues, aunque el Reino de Dios no es de este mundo (Jn. 18, 36), en cuanto actúa en el mundo, está sujeta a las realidades de la vida terrena. Por estas razones la Iglesia participa de la condición externa de la sociedad humana para cuyo progreso son necesarios los bienes temporales, así: "Las realidades terrenas y las sobrenaturales están estrechamente unidas entre sí, y la misma Iglesia usa los medios temporales en cuanto su propia misión lo exige" (Vaticano II, 1965a, 76) ${ }^{[84]}$.

La administración y la enajenación de los bienes temporales deben estar alejadas del espíritu del mundo, ya que "No impulsa a la Iglesia ambición terrena alguna. Solo desea una cosa: continuar, bajo la guía del Espíritu Santo, la obra misma de Cristo" (Vaticano II, 1965a, 3). Ella concibe su misión al servicio de la humanidad con la ayuda de los bienes temporales, adquiridos para tal fin (Cisternino, 1999), los cuales deben ser usados y administrados de manera particular según su misión lo exige, es así como se encuentra en las realidades temporales ayudas para avanzar hacia las realidades sobrenaturales (Vaticano II, 1965a, 76).

La administración y la enajenación de bienes que adelantan los Institutos se realiza en el contexto del mundo en el que Instituto actúa y donde las transformaciones económicas y sociales suceden con gran velocidad y dinamismo, por lo que ofrece permanentemente productos, mercados y realidades económicas nuevas, muchas de las cuales deben adquirirse según las obras apostólicas que se tienen a fin de ofrecer un servicio cualificado. Sin ignorar esta realidad, y sabiendo también que el incremento patrimonial hace parte de la administración de bienes, los institutos religiosos no deben sumergirse en un mundo económico irracional y asfixiante, pues este siempre estará dominado por los poderosos y potentados de este mundo, que imponen normas en contra las que no se debe tratar de competir. Los Institutos deben fomentar un estilo de vida económico y una administración que favorezca a su misión y a su pobreza, que sirva eficazmente a los hombres, 
acoja a los pobres y ofrezca una propuesta alternativa que renuncie al afán de riquezas y de acumulación de bienes como signo del Evangelio (Arenas y Torres, 2006, p. 11).

En cuanto al fundamento jurídico y pastoral de los bienes cabe agregar que, si la Iglesia necesita de los bienes temporales para cumplir su misión, entonces el carisma, la identidad, la vida y misión de cada uno de estos bienes se manifiesta no solo como espíritu, sino también como estructuras legales a través de las cuales los Institutos actúan, y dentro de estas está la estructura económica.

Los institutos religiosos tienen derecho a los bienes temporales, estos les pertenecen y hacen parte del patrimonio de la Iglesia; tales bienes son bienes eclesiásticos (Juan Pablo II, 1983, c. 1254, §1) y por ello deben administrarse observando lo que disponen las leyes canónicas, pero también, dada su condición particular, según las Reglas o Constituciones propias, es decir, según el fin que le corresponde a la luz de la misión carismática del Instituto. Ante la especificidad del carisma, la ley de la Iglesia exige que cada Instituto establezca normas particulares relativas al uso y administración de los propios bienes de conformidad con las exigencias de la pobreza religiosa. Se trata, en la práctica, de anexar a las normas canónicas generales algunas normas particulares más precisas para regular la administración de los bienes de cada Instituto (Arenas y Torres, 2006, p. 10$)^{[85]}$.

La posibilidad de poseer bienes es lícita; tal licitud, además de estar determinada en el CIC (Juan Pablo II, 1983, cc. 1254 y 634), es reconocida por el Concilio y es aplicable a la administración y enajenación.

El pensamiento del Concilio Vaticano II resulta muy sugerente en materia de administración de bienes de institutos religiosos, pues de este se desprende que dicha administración deba ser evangélica, prudente, sabia, fraterna, transparente, corresponsable, eficiente, austera, profética, apostólica, comunitaria, de comunión (Arenas y Torres, 2006, pp. 25-27, 87-89) y jurídica.

En efecto, los bienes temporales, administrados con toda la diligencia posible, permiten a los institutos religiosos cumplir su misión de manera más completa (Arenas y Torres, 2006, p. 9) ${ }^{[86]}$ y apropiada si se tiene presente que son un medio para alcanzar un fin mayor. Una recta administración de bienes es una tarea difícil pero necesaria; las disposiciones canónicas sobre esta materia son una ayuda válida y sus exigencias son importantes, sin embargo, no se debe desconocer que esta tarea no solo pretende conservar, acrecentar o distribuir los bienes, para lo que cuentan con la ayuda de peritos expertos, sino que al tener presente el tipo de sujeto al que tales bienes pertenecen y su finalidad, la administración tiene un fin también trascendente.

El verdadero sentido de los bienes materiales, tanto en sí mismos como en su relación con la persona humana, está en ser usados como ayudas en la búsqueda del bien común ( $A A 31$ ) o como medios para el desarrollo del hombre a fin de que avance hacia su salvación, hacia su vida sobrenatural. Al colaborar en esta tarea, los bienes quedan sumergidos dentro de tal realidad, la cual los ennoblece, los eleva a una condición nueva y les asigna un lugar y una tarea propia en la vida y en la misión del hombre, de la Iglesia y de los institutos religiosos.

Si bien los bienes son necesarios para la vida y el desarrollo de las personas naturales, morales o jurídicas, estos en sí no son un fin último, pues tienen la condición de medios y como tales deben ser entendidos.

\section{Referencias}

Alberigo, G. (1999). Storia del Concilio Vaticano II (I-V). Lovaina: Peeters.

Alberigo, G. (ed.). (2000). Conciliorum Oecumenicorum Decreta. Bolonia.

Alberigo, G., y Magistretti, F. (eds.). (1975). Constitutionis Dogmaticae Lumen Gentium Synopsis Historica. Bolonia: Fundación para las Ciencias Religiosas.

Arenas, E., y Torres, F. (2006). Vita consacrata ed economia. Manuale per l'amministrazione degli istituti religiosi. Ancora.

Bandera, A. (1971). La consacrazione a Dio per mezzo dei consigli evangelici II. Vita Consacrata, 6-7. 
Bettazzi, L. (1968). I presbiteri e la povertà volontaria. En A. Favale (ed.), I sacerdoti nello spirito de Vaticano II (pp. 958-975). Turín: Leumann.

Beyer, J. (1966). De statu vitae professione consiliorum evangelicorum. Periodica, 55, 3-58.

Beyer, J. (1975). Vita Consacrada 11. Milán: Ancora.

Boni, A. (1997). Vangelo e vita religiosa. Rilettura teologica e storico-giuridica delle fonti (Spicilegium Pontificii Athenaei Antoniani 32). Revista de Ciencias Religiosas, 71(1), 133.

Caprile, G. (1959). Il Concilio Vaticano II. Cronache del Concilio Vaticano II. L'annunzio e la preparazione (vol. I). Roma: La Civilta Cattolica.

Cenalmor, D., y Miras, J. (2004). El derecho de la Iglesia. Curso básico de derecho canónico. Estudios Eclesiásticos, 79(31).

Cisternino, M. (1999). L'uso dei beni temporali da parte dei chierici dal Concilio Vaticano II al CJC 1983. Roma: Pontificia Università Lateranense.

Conti, M. (1975). Povertà di Cristo e povertà della Chiesa. En VitaCon 11 (pp. 481-486).

Daniélou, J. (1974). Il carattere specifico della vita religiosa. En VitaCon 10.

De Paolis, V. (1983). Gli istituti di vita consacrata nella Chiesa. En A. Longhitano (ed.), La vita consacrata. Codice del Vaticano II (pp. 53-144). Bolonia.

Fagiolo, V. (1988). Perfectae Caritatis. Decreto sul rinnovamento della vita religiosa, Collana Concilio Vaticano II. Roma.

Fanfani, L. (1965). Genesi dello schema. En A. Favale,La Costituzione dogmatica sulla Chiesa (pp. 11-73). Libreria Editrice Vaticana.

Galot, J. (1978). Consacrazione battesimale e consacrazione religiosa. En Vita Consacrata 14 (pp. 590-600).

Galot, J. (1979). Il carisma della vita religiosa e le sue note specifiche. En Vita Consacrata 15 (pp. 501-511).

Gambari, E. (1966a). La costituzione "Lumen Gentium” e la vita religiosa. En Vita Religiosa 2 (pp. 34-44).

Gambari, E. (1966b). La vita religiosa dono di Dio alla Chiesa. En Vita Religiosa 2 (pp. 299-308).

Gambari, E. (1970). Elementi costitutivi e caratteristici della "vita religiosa”. En VitaRel 6 (pp. 98-106; 156-165).

Gambari, E. (1971). Manuale della vita religiosa alla luce del Vaticano II (I-II). Roma: Centro Mariano Monfortano.

Garceranth Ramos, I. (2011). Administración y enajenación de bienes temporales eclesiásticos a la luz del Concilio Vaticano II. Universitas Canonica, 28(44), 79-131. Recuperado de https://derechocanonico.javeriana.edu.co/d ocuments/2804305/2804549/Revista+Canónica+2011.pdf/0f063b9f-4d35-4fb2-83fb-480b9bb29838

Ghirlanda, G. (1977). Ecclesialità della vita consacrata. En A. Longhitano (ed.), La vita consacrata. Codice del Vaticano II (pp. 13-52). Bolonia.

Ghirlanda, G. (1984). La vita consacrata nella vita della Chiesa. Informationes SCRIS, 10, 79-96.

Ghirlanda, G. (1992). Carisma di un istituto e sua tutela. VitaCon 28 (pp. 465-477; 554-562).

Juan Pablo II. (1983). Código de Derecho Canónico (CIC). Recuperado de http://www.vatican.va/archive/ESL00 20/_INDEX.HTM

Juan XXIII. (1959). Questa festiva ricorrenza. Acta Apostolicae Sedis (AAS), año 51, serie III, volumen 1, 65-69. Recuperado de http://www.vatican.va/archive/aas/documents/AAS-51-1959-ocr.pdf

Juan XXIII. (1960). Motu Proprio, Superno Dei nutu. Acta Apostolicae Sedis (AAS), año 52, serie III, volumen II, 433-437. Recuperado de http://www.vatican.va/archive/aas/documents/AAS-52-1960-ocr.pdf

Lio, E. (1966). I Religiosi e il Concilio Vaticano II. En VitaRel 2 (pp. 20-33).

Molinari, P., y Gumpel, P. (eds.). (1985). Il capitolo VI “De Religiosis” della Costituzione dogmatica sulla Chiesa. Milan: Ancora.

Oliver, B. (1981). Il carisma della vita religiosa nel Concilio e nei documenti post-conciliari. En Vita Consacrata 17 (pp. 323-340).

Pablo VI. (1964). Magno gaudio. Testimonio público y social de la vida religiosa. Recuperado de http://www.clerus.or $\mathrm{g} /$ clerus/dati/2004-05/11-15/23051964 
Pablo VI. (1965). Declaración Dignitatis humanae. Sobre la libertad religiosa. Vatican.va. Recuperado de http://www.vatican.va/archive/hist_councils/ii_vatican_council/documents/vat-ii_decl_19651207_digni tatis-humanae_sp.html

Rocco, U. (1966). I religiosi. En A. Favale (ed.), La Costituzione dogmatica sulla Chiesa (pp. 757-776). Turín: Leumann.

Ruíz Jurado, M. (1989). Vida consagrada y carisma de los fundadores. En R. Latourelle (ed.), Vaticano II: balance y perspectivas veinticinco años después (1962-1987) (pp. 801-815). Salamanca: Ediciones Sígueme.

Said, M. (1979). La vita consacrata mediante la professione dei consigli evangelici. VitaCon, 15, 27-34.

Schoenmaeckers, M. (1983). Genese du Chapiter VI "De Religiosis. de la Constitution Dogmatique sur l'Eglise "Lumen Gentium". Roma: Pontificio Istituto Biblico.

Schouppe, J. P. (2007). Derecho patrimonial canónico. Pamplona: Universidad de Navarra.

Schulte, R (1968). La vida religiosa como signo. En G. Baraúna, La Iglesia del Vaticano II. Estudios en torno a la Constitución conciliar sobre la Iglesia (1091-1122). Barcelona: Juan Flors.

Sebastian, F. (1966). Historia capitis VI constitutionis “Lumen Gentium”. En Teología espiritual (pp. 349-363).

Sericoli, C. (1966). Il rinnovamento dei religiosi. En Vita Religiosa 2 (pp. 483-495).

Sugawara, Y. (1997). Religious poverty. From Vatican Council II to the 1994 Synod of Bishops. Roma: Pontificia Universidad Gregoriana.

Vaticano II. (1959). Celebrazione dei secondi vespri nella solennità di pentecoste. Omelia del Santo Padre Giovanni XXIII. Roma: Libreria Editrice Vaticana. Recuperado de https://w2.vatican.va/content/john-xxiii/it/homilies/1959/ documents/hf_j-xxiii_hom_19590517.html

Vaticano II. (1963). Sacrosanctum Oecumenicum Concilium Vaticanum Secundum. Schemata Constitutionum et Decretorum de quibus disceptatibur in Concilii sessionibus (series I, II, III, IV). Roma: Typis Polyglotis Vaticanis.

Vaticano II. (1964). Acta et Documenta Concilio Oecumenico Vaticano II Apparando. Series II (Praeparatoria) (I-IV). Roma: Libreria Editrice Vaticana.

Vaticano II. (1964). Lumen Gentium. Constitución Dogmática sobre la Iglesia. Roma: Libreria Editrice Vaticana. Recuperadodehttp://www.vatican.va/archive/hist_councils/ii_vatican_council/documents/vat-ii_const_196 41121_lumen-gentium_sp.html\#*

Vaticano II. (1965a). Gaudium et Spes. Constitución Pastoral sobre la Iglesia en el mundo actual. Roma: Libreria Editrice Vaticana. Recuperado de http://www.vatican.va/archive/hist_councils/ii_vatican_council/documents/vat-ii_ const_19651207_gaudium-et-spes_sp.html

Vaticano II. (1965b). Perfectae Caritatis. Decreto sobre la adecuada renovación de la vida religiosa. Roma: Libreria Editrice Vaticana. Recuperado de http://www.vatican.va/archive/hist_councils/ii_vatican_council/documents /vat-ii_decree_19651028_perfectae-caritatis_sp.html

Vaticano II. (1965c). Presbyterorum Ordinis. Decreto sobre el ministerio y vida de los presbiteros. Roma: Libreria Editrice Vaticana. Recuperado de http://www.vatican.va/archive/hist_councils/ii_vatican_council/documents/vat-ii_ decree_19651207_presbyterorum-ordinis_sp.html

Vaticano II. (1970). Acta Synodalia Sacrosancti Concilii Oecumenici Vaticani II.Periodus Prima. Congregationes Generales I-XXX (vol. I) (partes I-III). Roma.

Vaticano II. (1972). Acta synodalia sacrosancti Concilii Oecumenici Vaticani II. Periodus secunda. Congregationes generales $L I X-L X I V$ (vol. II). Roma.

Vaticano II. (1973). Acta synodalia sacrosancti Concilii Oecumenici: Processus verbales (vol. V). Roma.

Vaticano II. (1976). Acta synodalia sacrosancti Concilii Oecumenici Vaticani II. Periodus tertia. Congregationes generales CXXIII- CXXVII (vol. III). Roma. 


\section{Notas}

* Artículo de reflexión

[1] Existen otros documentos del Concilio Vaticano II de los que se hará referencia en el momento oportuno, pero que no son estudiados de igual manera como se hace con los tres documentos básicos escogidos: "Lumen Gentium" (capítulo VI), "Presbyterorum Ordinis" (no. 17) y "Perfectae Caritatis" (no. 13).

[2] La traducción al castellano de los documentos conciliares está tomada de la Biblioteca de Autores Cristianos (BAC): Documentos del Vaticano II, Constituciones, Decretos y Declaraciones, 1972.

[3] Esta comisión tuvo como presidente al cardenal Dominico Tardini, secretario de Estado del Romano Pontífice y prefecto de la Sagrada Congregación para los Asuntos Eclesiásticos Extraordinarios, y como secretario a monseñor Pericle Felici, prelado de la Sacra Rota Romana, y estuvo conformada en un principio por diez miembros a los cuales, posteriormente, fue agregado uno más (Vaticano II, 1959).

[4] $\mathrm{AD}$ I/ II, I, X-XI, 1C/59.

[5] AD I/IV, I/1, XI-XII, 2C/59.

[6] En total se hicieron 2812 interpelaciones. De las 2594 autoridades eclesiásticas consultadas, se recibieron 1998 respuestas, es decir, un 77,0 \% de los requeridos; de los 156 Superiores Religiosos consultados se recibieron 101 respuestas, es decir, un 64,7 \%. Además, de los 62 Institutos de Estudios Superiores, entre los cuales se encuentran: 14 universidades y ateneos romanos, 32 universidades católicas fuera de Roma, 11 facultades de estudios eclesiásticos, 5 facultades de teología de universidades estatales, respondieron 51, dándose un 82,2 \% de respuestas. En el total de consultados no se cuentan los dicasterios de la Curia Romana. Para ampliar información sobre este tema véase Caprile, G. (1959) y AD I “Indices”, 209-211, 407, 429. Las cifras reportadas en este "Índices" en cuanto al tema de los Superiores Religiosos son ligeramente diferentes según lo dicho en las páginas 209 y 407 , pero esto no afecta la prueba del elevado número de postulados presentados.

[7] Consilia et vota Episcoporum ac Praelatorum, AD I/II, I-VII. Las partes I, II, III contienen las respuestas de Europa; partes IV de Asia; partes V de África; partes VI de América Septentrional y central, y partes VII de América Meridional-Oceanía.

[8] Superiores Generales Religiosorum, AD I/II, II, VIII.

[9] Appendix voluminis II, Analyticus Conspectus Consiliorum et Votorum quae ab Episcopis et Praelatis data sunt, AD I, I-II.

[10] Studia et vota Universitatum et Facultatum Ecclesiasticarum et Catholicarum, pars I, 1-2, Universitates et Facultates in Urbe, pars II, Universitates et Facultates extra Urbem, AD I/IV.

[11] Proposita et monita Sacrarum Congregationum Curiae Romanae, AD I/III.

[12] AD I, Indices.

[13] El 3 de noviembre de 1959 la Secretaría de la Comisión Antepreparatoria comenzó a remitir las propuestas a los dicasterios de la Curia Romana competentes y en la misma fecha a los miembros de las Comisiones Antepreparatorias. Para ampliar la información sobre este tema véase $A D$ I/III, X, 2/59; $A D$ I/III, XI-XII, 69-78/59.

[14] Para el estudio histórico se recomiendan los siguientes autores: Alberigo (1999), Caprile (1959), Alberigo y Magistretti (1975, p. 609), Fanfani (1965), Sebastian (1966) y Molinari y Gumpel (1985, pp. 18-83).

[15] La presentación de propuestas no obligaba a elaborar documentos con argumentos teológicos, dogmáticos, pastorales, canónicos o morales. Aunque algunos hicieron escritos extensos, otros solo presentaron, de manera breve, temas que a su juicio debían considerarse durante el Concilio. En todo caso, la Comisión Antepreparatoria debía atender y catalogar todos los postulados sugeridos.

[16] AD I, Appendix II, I-II.

[17] El Padre Molinari y Padre Gumpel argumentan que los postulados de los Superiores Generales y de la Sagrada Congregación para los Religiosos poco sugirieron en relación con la doctrina teológica de la vida religiosa. Con excepción del Prepósito General de la Compañía de Jesús, Padre J. B. Janssens, quien resaltaba la necesidad de exponer de manera clara esta doctrina. Se resaltan, además, los aportes del R. Padre Luciano Rubio, Prior General de los Frailes Eremitas de San Agustín; R. Padre Kilianus Healy, Prior General de la Orden de los Frailes de la Beata Virgen María del Monte Carmelo y el R. Padre Gilberto Fini, Superior General de la Congregación de los Santísimos Estigmas de Nuestro Señor Jesucristo. Así como fue poco presentado por los Superiores Generales, 
de menor interés resultaba este tema para las universidades católicas. AD I/II, VIII, 95-96, 101, 125, 179. Para más información sobre este tema véase Molinari y Gumpel (1985, VI, 22).

[18] El Motu Proprio Superno Dei nutu, del 5 de junio de 1960, creó una Comisión Preparatoria Central y diez Comisiones Preparatorias sobre asuntos específicos: Teológica, de los obispos y del gobierno de las diócesis, de la disciplina del clero y del pueblo cristiano, de los religiosos, de la disciplina de los sacramentos, de la sagrada liturgia, de los estudios y de los seminarios, para las Iglesia Orientales, para las misiones y para el apostolado de los laicos. La Comisión Central estaba integrada por los presidentes de las diferentes Comisiones, un secretariado y otros miembros nombrados por el Santo Padre (Juan XXIII, 1960; Caprile, 1959, pp.185-187, 193, 209).

[19] De Ecclesia, Caput. V, De statibus evangelicae adquirendae perfectionis, AD II/III, I, 152-154.

[20] Relatio, animadversiones sodalium et suffragia sodalium, AD II/II, III, 1084-1115.

[21] El Schema Constitutis Dogmaticae De Ecclesia consta de los siguientes capítulos: capítulo 1: "De Ecclesiae militantis natura"; capítulo 2: "De membris Ecclesiae militantis eiusdemque necessitate ad salutem"; capítulo 3: "De Episcopatu ut supremo gradu Sacramento Ordinis et de Sacerdotio"; capítulo 4: "De Episcopis residentialibus"; capítulo 5: "De statibus evangelicae acquirendae perfectionis"; capítulo 6: "De laicis"; capítulo 7: "De Ecclesiae magistero"; capítulo 8: "De auctoritate et de oboedientia in Ecclesia"; capítulo 9: "De relationibus inter Ecclesiam et Statum"; capítulo 10: "De necessitate Ecclesiae annuntianti Evangelium omnibus gentibus et ubique terrarum”, y capítulo 11: “De Oecumenismo” (Vaticano II, 1963, 1970).

[22] Capítulo V. De statibus evangelicae acquirendae perfectionis, AD II, II, 32-35. Ver el documento sobre los religiosos en el apéndice 1 , texto $\mathrm{A}$.

[23] Relatio Em.mi P.D. Alfredi Card. Ottaviani Praesidis Commissionis de Doctrina Fidei et Morum: "Cura eorum qui praeparaverunt schema fuit, ut quam maxime pastorale esset, biblicum et etiam accessibile captui etiam multitudinum, non scholasticum sed potius forma quadam actualiter ab omnibus comprehendenda" (Vaticano, 1970, I/IV, p. 121).

[24] También están las intervenciones del 4 y 5 de diciembre de 1962, de los cardenales Leo Joseph Suenens y Juan Bautista Montini (Vaticano, 1970, I/IV, pp. 222-227, 291-294).

[25] En el "Adumbratio Schematis Constitutionis Dogmaticae" se expone la propuesta de la Conferencia Episcopal AlemanaAustriaca (Vaticano, 1970, I/IV, pp. 608-639).

[26] Los miembros de la Comisión de Coordinación fueron anunciados en el OR del 17 al 18 de diciembre de 1962.

[27] En estas sesiones plenas, la Comisión de Coordinación estableció el modo de coordinar y seguir los trabajos de las diferentes Comisiones. Cada miembro tuvo la tarea de seguir de cerca algunos esquemas y de ser su relator a fin de comunicar el trabajo de cada Comisión a las otras Comisiones para así realizar un trabajo más integrado. El cardenal Suenens era el relator para las Comisiones De Ecclesia y De Beata Maria Virgine; el cardenal Döpfner era el relator para la Comisión De Religiosis.

[28] Este esquema estaba compuesto de cuatro capítulos: capítulo I: "De Ecclesiae misterio"; capítulo II: “De Episcopis”; capítulo III: “De Laicis”, y capítulo IV: “De Beata Maria Virgine”.

[29] Propositiones Em.mi Iulii Card. Doepfner: "status perfectionis adquirendae est status charismaticus, originem ducens ex vita et doctrina Christi, formam iuridicam ex institutione Ecclesiae obtinens, membra ex utroque statu divinae institutionis (scl. Hierarchia et Laicatus) complectens. Fundamentum theologicum sunt consilia evangelica, scl. paupertas, virginitas, oboedientia, quae sunt signa redemptionis (exinanitionis nempe crucis et glorificationis resurrectionis), quibus sicut vita Redemptoris signata era ita etiam corpus Christi mysticum carere numquam potest. Quae signa enim patefaciunt speciali modo mysterium Ecclesiae eamque ostendunt esse locum, quo crux Christi erecta manet et communitas redemptorum Christo eiusque eschatologicae gloriae obviam it. Unde qui ad statum perfectionis adquirendae vocantur, primarie non ut propriae sanctificationi vivant vocantur, sed ut indolem Ecclesiae repraesentent et Christo in ea serviant (et sic eo ipso propriam perfectionem assequantur)" (Caprile, 1959, p. 331).

[30] Propositiones Commissionis de Concilii laboribus coordinandis. Schema Constitutionis Dogmaticae De Ecclesia: capítulo I: "De Ecclesiae misterio" (capítulo I y II del esquema anterior del año 1962); capítulo II: "De institutione hierarchica Ecclesiae et in specie: de episcopis" (capítulo III, IV, VII parte VIII quaedam); capítulo III: "De Laicis" (capítulo VI, VII quaedam, VIII quaedam), y capítulo IV: "De statibus evangelicae acquirendae perfectionis" (capítulo V). 
[31] La Comisión de Coordinación discutió y formuló los cuatro capítulos de la Constitución De Ecclesia así: capítulo I: "De Ecclesiae Mysterio"; capítulo II: De "Constitutione Hierarchica Ecclesiae, et in specie de Episcopatu” en la Sessio Secunda, Congregatio 4 del 28 de marzo de 1963; capítulo III: “De populo Dei et speciatim de laicis”, y capítulo IV: "De vocatione ad sanctitatem in Ecclesia en la Sessio tertia", Congregatio 2 del 4 de julio de 1963. Para ampliar la información véase notas a pie de página de Vaticano II (1973, V/I, p. 451, 574).

[32] Molinari-Gumpel (1985) comentan que en las sesiones plenarias del 5 al 9 de marzo la Comisión Doctrinal discutió y aprobó el capítulo I sobre el misterio de la Iglesia. El capítulo II, sobre la constitución jerárquica de la Iglesia, se aprobó en las reuniones del 9 al 13 de marzo; el capítulo III sobre los laicos en la sesión del 15 al 18 de mayo, y el capítulo IV en el 27 y 28 de mayo, para lo cual se creó, intempestivamente, una nueva subcomisión (pp. 32-33).

[33] Los capítulos I y II fueron enviados a los Padres conciliares por orden del Santo Padre Juan XXIII, el 23 de abril de 1963 (Vaticano II, 1972, II/I, p. 215); en cambio, los capítulos III y IV fueron enviados a los Padres del Concilio por disposición del Papa Pablo VI, el 19 de julio de 1963 (Vaticano II, 1972, II/ I, p. 256).

[34] Ver apéndice, texto B.

[35] Un mes antes de la discusión plenaria del capítulo IV De Ecclesia en la Comisión Doctrinal, una Subcomisión Mixta, conformada por miembros de la Comisión Doctrinal y de la Comisión del Apostolado de los Laicos, había manifestado que el tema de la vocación universal a la santidad debía ser tratado en un capítulo independiente al de los religiosos, por lo que requerían de una separación radical (Vaticano II, 1976, III/I, p. 309).

[36] Aunque, en general, se trataba del mismo texto aprobado por la Comisión de Coordinación, el documento entregado a los Padres tenía algunas diferencias leves en su redacción, por lo cual se cambiaban o se suprimían algunas pocas palabras.

[37] Tantas intervenciones orales y animadversiones escritas sobre el esquema general de la Constitución De Ecclesia soportan lo dicho. Para ampliar información sobre este tema véase Vaticano II (1972, II/I, pp. 343-364, 365-387, 399-418, 467-801).

[38] En la relatio del cardenal Suenens está escrito: "Haberemus tunc Constitutionem in 5 capitibus divisam: 1. De Ecclesiae Mysterio, 2. De Populo Dei in genere, 3. De constitutione hierarchica Ecclesiae, 4. De Laicis in specie y 5. De vocatione ad sanctitatem in Ecclesia" (Vaticano II, 1973, V/I, p. 594). La Comisión de Coordinación dividió en dos partes el capítulo III: "De Populo Dei et speciatim de laicis"; así, creó un primer capítulo: "De populo Dei in genere”, que iría antes del capítulo referido a la jerarquía en la Iglesia, y un segundo capítulo: "De laicis in specie”.

[39] El primer fascículo con enmiendas se entregó el 29 de septiembre y el segundo el 9 de octubre de 1963 (Vaticano II, 1972 , II/I, pp. 282-336).

[40] Se presentó un esquema con cinco capítulos: capítulo I: "De Ecclesiae Mysterio”; capítulo II: "De membrorum in Ecclesia Christi aequalitate et inaequalitate”; capítulo III: “De Constitutione Hierarchica Ecclesiae”; capítulo IV: "De statibus perfectionis adquirendae”, y capítulo V: “De laicis. Patrum Orationes”, Exc.mus P.D. Hermenegildus Florit (Vaticano II, 1972, II/I, p. 357).

[41] Entre quienes defendían la propuesta del capítulo IV, entre otros, se encontraban: Exc.mus P. D. Andreas M. Charue, Episcopus Namurcensis; Exc.mus P. D. Iulius Card. Doepfner, Archiepiscopus Monacensis et Frisingensis, quien habló a nombre de los 79 obispos de lengua alemana y de los países escandinavos (Vaticano II, 1972, II/III, pp. 382-384, 603-605). Exc.mus P. D. Isidorus Marcus Emmanuel, Episcopus Spirensis; Exc.mus P. D. Carolus Ioseph Leiprecht, Episcopus Rottenburgensis; Exc.mus P. D. Eduardus Schick, Episcopus tit. Araditanus, aux. Fuldensis (Vaticano II, 1972, II/IV, pp. 30-31, 41-42, 70-71).

[42] Teólogos de la Compañía de Jesús elaboraron el escrito Adnotationes quaedam theologicae ad caput IV Schematis De Ecclesia, que exponía argumentos para el cambio del capítulo IV (Schoenmaeckers, 1983, pp. 61-62). Además, en relación con estos puntos señalados cabe recalcar las intervenciones en el aula del Exc.mus P. D. Iacobus Corboy, Episcopus Monzensis; Rev.mus P. D. Antonius de Hornedo Correa, Praefectus apostolicus S. Francisci Xaverii; Exc.mus P. D. Richardus Lester Guilly, Episcopus Georgiopolitanus; Exc.mus P. D. Robertus Hodapp, Episcopus Belizensis; Exc.mus P. D. Adam Kozlowiecki, Archiepiscopus Lusakensis; Exc.mus P. D. Aloisius Manresa Formosa, Episcopus Altentis; Exc.mus P. D. Aldus Patroni, Episcopus Calicutensis; Exc.mus P. D. Victor Sastre, Archiepiscopus tit. Beroensis; Exc.mus P. D. Laurentinus Trevor Picachy, Episcopus Iamshedpurensis (Vaticano II, 1972, II/IV, pp. 140-142, 152-154, 195-197, 221-223, 240-244, 256-257, 288-290, 311-313, 330-331).

[43] En la Congregación General 56 hubo 8 intervenciones orales; en la 57, 7; en la 58, 13, y en la 59, 20 (Vaticano II, 1972, II/ III, pp. 368-389, 590-627, 632-669; II/IV, pp. 29-76). 
[44] En la Congregación General 58 del 30 de octubre de 1963 se propuso el cierre del debate del capítulo IV, ante lo cual algunos Padres reaccionaron y fue concedido abordarlo de nuevo en la Congregación General 59; en esta fueron llamados a hablar solo 20 Padres (Vaticano II, 1972, II/IV, pp. 27-28). Las intervenciones hechas durante la Congregación General 59 estuvieron sometidas a tensiones y limitaciones por parte del moderador, el cardenal Döpfner (Vaticano II, 1972, II/ IV, pp. 27-28); este cerró el debate del capítulo IV en la Congregación General 59 a pesar de que debían escucharse aún otros Padres que no habían renunciado a su derecho a intervenir, por lo que debieron entregar por escrito su parecer (Vaticano II, 1972, II/IV, pp. 31, 33, 41, 54, 55, 64, 76). Exc.mus P. D. Laureanus Card. Rugambwa, Episcopus Bukobaensis, (Vaticano II, 1972, II/IV, pp. 85-86); Rev.mus P. D. Ioannes B. Janssens, Praepositus Generalis S. I. (Vaticano II, 1972, II/IV, pp. 226-228).

[45] Esta realidad fue constatada por el cardenal Döpfner y al mismo tiempo el cardenal Browne pedía que se tuviera en cuenta tal situación en las comisiones respectivas (Vaticano II, 1972, II/IV, pp. 554-556).

[46] La forma como el cardenal Döpfner había moderado el debate del capítulo IV hacía que quienes se sentían violados en sus derechos buscaran la manera de corregir las irregularidades presentadas; para ello el cardenal Döpfner los citó a una reunión el 6 de noviembre (Vaticano II, 1972, II/IV, p. 475). En dicha reunión acordaron presentar un resumen de los pareceres de quienes no habían intervenido en el debate del capítulo IV, el cual sería leído en el aula de la Congregación General 62 del 7 de noviembre. Sin embargo, la sorpresa de los Padres que elaboraron dicho resumen fue grande al notar que en el aula se leyo otro escrito diferente al elaborado por ellos (Vaticano II, 1972, II/IV, pp. 554-555).

[47] Molinari y Gumpel (1985) dan cuenta de este momento histórico. El grupo creado se conoció con el nombre de Secretariado de los Obispos, este tuvo una presencia muy fuerte y una incidencia positiva, además elaboró un escrito llamado Postulata, que contenía 653 firmas de Padres conciliares, al cual se adhirieron después otros Padres (Vaticano II, 1972, II/IV, pp. 355-359). Este escrito fue entregado al cardenal M. Browne, Vicepresidente de la Comisión Doctrinal, y al P. Felici, Secretario General del Concilio, los cuales lo remitieron al Romano Pontífice quien luego nombró al P. Pacifico Prantoni, O. F. M. como miembro de la Comisión De Religiosis (Molinari y Gumpel, 1985, pp. 64-70).

[48] Beyer (1975), por su parte, considera que el Secretariado de los Obispos no logró introducir en el capítulo sobre los religiosos los elementos importantes de esta forma de vida, por lo que reconoce su trabajo como incompleto (p. 744).

[49] En carta del 13 de abril de 1964 la Comisión De fidei et Morum envió a la Comisión de Coordinación el texto revisado del nuevo documento De Ecclesia (Vaticano II, 1970, Appendix Altera, pp. 9-70). El 29 de abril de 1964 la Comisión Fidei et Morum remitió a la Comisión de Coordinación nuevos estudios hechos al documento De Ecclesia al cual se le anexó una relación (Vaticano II, 1973, V/II, pp. 482-493).

[50] El discurso del Romano Pontífice hizo que el Secretariado de los Obispos adelantara una nueva acción ante los Padres conciliares, aún en receso de las sesiones plenarias, con el fin de mejorar el documento sobre la Iglesia por ellos recibido. Específicamente buscaban revisar la parte concerniente a los religiosos para enviar el tema de la vocación a la santidad a uno de los primeros capítulos del esquema y darle, definitivamente, un capítulo propio al tema De Religiosis.

[51] El esquema estaba dividido así: capítulo I: "De Ecclesiae misterio"; capítulo II: "De populo Dei”; capítulo III: "De Constitutione hierarchica Ecclesiae et in specie de episcopatu"; capítulo IV: "De laicis"; capítulo V: "De universali vocatione ad sanctitatem in Ecclesia"; capítulo VI: "De Religiosis"; capítulo VII: "De indole escatologica vocationis nostrae ac de nostra unione cum Ecclesia caelesti”, y capítulo VIII: "De Beata Maria Virgine Deipara in mysterio Christi et Ecclesiae”. Además de este texto se entregó a los Padres una Relatio Generalis de cada capítulo nuevo, junto con una Relationes de singulis numeris.

[52] Sobre este documento ver Apéndice, texto C.

[53] El esquema final de la Constitución sobre la Iglesia Lumen Gentium quedó así: Capítulo I: "De Ecclesiae misterio” (nn.1-8); capítulo II: "De populo Dei" (nn. 9-17); capítulo III: "De Constitutione hierarchica Ecclesiae et in specie de episcopatu” (nn. 18-29); capítulo IV: “De laicis" (nn. 30-38); capítulo V: "De universali vocatione ad sanctitatem in Ecclesia” (nn. 39-42); capítulo VI: "De Religiosis" (nn. 43-47); capítulo VII: "De indole escatológica Ecclesiae peregrinantis eiusque unione cum Ecclesia caelesti” (nn. 48-51), y capítulo VIII: "De Beata Maria Virgine Deipara in mysterio Christi et Ecclesiae” (nn. 52-69) (Vaticano II, 1976, III/VIII, pp. 784-837).

[54] Ver el texto definitivo en el Apéndice, texto D.

[55] Sobre los elementos de los consejos evangélicos véase: Beyer (1975, pp. 742-762, 636-642, 845-859); Ruíz Jurado (1989, pp. 801-815); Rocco (1966, pp. 757-776); Sugawara (1997, pp, 40-61); Daniélou (1974, pp. 521-531); Conti (1975, pp.481-486); Galot (1978, pp. 590-600); Galot (1979, pp. 501-511); Bandera (1971, pp. 345-358, 431-441, 521-531, 609-616); Boni (1997, 
pp. 265-276); Said (1979, pp. 27-34); Gambari (1971, pp. 235-249); Gambari (1966b, pp. 299-308); Gambari (1966a, pp. 34-44); Gambari (1970, pp. 98-106, 156-165); Sericoli (1966, pp. 483-495); Fagiolo (1988, pp. 9-17) y Oliver (1981, pp. 323-340).

[56] "La vita religiosa è essenzialmente un dono speciale fatto al Corpo Mistico di Cristo [...] per l'arricchimento della vita della Chiesa stessa”.

[57] "L’amore di Dio per la Chiesa, in quanto santa, si esprime nel modo più completo dando alla Chiesa uno stato di vita che forma la predilezione del cuore di Dio".

[58] El c. 575 del CIC, apropiándose de las enseñanzas del Concilio, dice: "Los consejos evangélicos, fundados en las enseñanzas y en los ejemplos de Cristo Maestro, son un don divino que la Iglesia ha recibido del Señor y con su gracia siempre conserva” (Juan Pablo II, 1983).

[59] Ghirlanda (1977) señala la diferencia que existe en este aspecto entre el consagrado y el presbítero: “Sia il 'consacrato' che il prete sono segno escatologico nella Chiesa e nel mondo, ma con la differenza che, mentre nel primo i tre consigli evangelici sono talmente connaturali alla sua vocazione che senza la pratica effettiva di essi la sua vita sarebbe svuotata di ogni senso, nel secondo invece il ministero sacerdotale non sarebbe svuotato di efficacia e senso, anche se dovesse mancare la pratica dei consigli, perché Cristo continua ad agire anche nell'atto posto da un ministro indegno" (p. 413).

[60] "Se la scelta di Dio è amore, la risposta a tale scelta sarà una risposta d'amore, in un dono di sé che permette di appartenere a Dio solo, per sempre. Questa risposta non è possibile che in Gesù Cristo, per lui, con e come lui; essa culmina nel suo sacrificio; perciò si fa normalmente nella Eucaristia. Per essere salda e stabile, la consacrazione suppone la volontà di donarsi totalmente, in maniera definitiva, anche se i vincoli restano temporanei, e diversi dai voti” (Beyer, 1975, pp. 746-747).

[61] En cuanto a la naturaleza de la consagración, Lumen Gentium no da, en efecto, una solución satisfactoria, pues la óptica en esta materia se fija más en los votos de religión y no en el acto de amor que es propio de la donación total. La perfección de la consagración se manejó según la dependencia de los vínculos sagrados, sin resaltar que esta es más perfecta en virtud de la donación por amor, que es su fundamento.

[62] "Cum in definitione dicatur consilia suscipi "per professionem", his verbis sufficienter indicatur agi non de mero spiritu Consiliorum, secundum quem omnes qui perfectionem consequi volunt vivere debent” (Vaticano II, 1972, II/VII, p. 109).

[63] "essi non sono più semplici consigli, ma per libera scelta sono passati “in formam praecepti” (Lio, 1966, p. 25).

[64] Recogiendo cuanto se ha dicho hasta este momento, el CIC (Juan Pablo II, 1983, c. 573, \$1), basado en las enseñanzas del Concilio, establece que: "La vida consagrada por la profesión de los consejos evangélicos es una forma estable de vivir en la cual los fieles, siguiendo más de cerca a Cristo bajo la acción del Espíritu Santo, se dedican totalmente a Dios como a su amor supremo, para que, entregados por un nuevo y peculiar título a su gloria, a la edificación de la Iglesia y a la salvación del mundo, consigan la perfección de la caridad en el servicio del Reino de Dios y, convertidos en signo preclaro en la Iglesia, prenuncien la gloria celestial”.

[65] “[...] colui che si consacra a Dio, può farlo soltanto perché Dio lo ha in antecedenza scelto per sé, l'ha consacrato a sé stesso" (Beyer, 1975, p, 637).

[66] "Nell'atto del battesimo Dio ha posto la sua mano su di noi, ci ha consacrato e ci ha unito alla sua vita. Tutta la vita cristiana non è altro che la risposta a questa chiamata fondamentale, a questa prima elezione di Dio. La nuova consacrazione si inserisce nella consacrazione battesimale" (Beyer, 1975, p. 637).

[67] Si bien la consagración está fundada en el bautismo, esta se realiza en la Eucaristía. Aunque este punto no fue considerado por la Lumen Gentium, es cierto que el bautismo forma el centro y el corazón de la consagración mediante los consejos evangélicos. Es en la Eucaristía donde se comprende que esta consagración no es tan solo amor de Dios, sino que también es amor de los hombres por amor a Dios.

[68] "Il primo elemento scaturisce dalla potenzialità del battesimo che nel seguace di Cristo raggiunge la pienezza della consacrazione a Dio con l'osservanza dei consigli evangelici e la forma stabile di vita totalmente orientata al conseguimento della perfezione della carità" (Fagiolo, 1988, p. 12).

[69] El CIC (Juan Pablo II, 1983, c. 574) recoge y adapta las enseñanzas conciliares sobre esta materia y, al respecto, señala: $\$ 1$. "El estado de quienes profesan los consejos evangélicos en esos institutos pertenece a la vida y a la santidad de la Iglesia; por ello todos en la Iglesia deben apoyarlo y promoverlo.\$2. "Dios llama especialmente a algunos fieles a dicho estrado, para que gocen de este don peculiar en la vida de la Iglesia y favorezcan su misión salvífica con el fin y el espíritu del instituto". 
[70] "Il legame con la Chiesa è molto più stretto e l'azione di lei è indispensabile quando la vita di consacrazione assume la figura di stato o de istituzione nella Chiesa stessa [...]. E' la Chiesa, che in unione al Signore e come istrumento dell'azione divina, conferisce questa consacrazione".

[71] "Infatti coloro che si obbligano in detto modo a vivere secondo i consigli evangelici non ritengono assolutamente nulla per sé, ma sono dati a Dio in tutto ciò che essi sono e hanno”.

[72] "La consacrazione [...] a Cristo nella Chiesa è per il bene della Chiesa”.

[73] "La vita religiosa si presenta come la proiezione della Chiesa: è quindi, solo in seno alla Chiesa e alla luce della Chiesa che si può conoscere la vita religiosa".

[74] "Status ergo religiosus, licet ad Ecclesiae structuram hierarchicam non spectet ad eius tamen vitam et sanctitatem ... pertinet": non habetur in textu priori; sed correspondet desiderio plurium Patrum. Est velut conclusio naturae et momenti status religiosi; nam ipse pertinet ad ipsam vitam "pneumaticam" et sanctitatem Ecclesiae. [...] Ergo status religiosus in omnia quae pertinent ad vitam Ecclesiae intrare potest et debet” (Vaticano II, 1976, III/I, pp. 318-319).

[75] "La vita religiosa fa parte della struttura dlla Chiesa in ragione del fine stesso della Chiesa che è la santità: essa fa parte della vita della Chiesa sia come espressione di santità, sia come mezzo o istrumento di santificazione".

[76] "Il carattere ecclesiale della vita consacrata è fondato sul battesimo e si vive nell'Eucaristia".

[77] Para ampliar información sobre este tema, véase Ghirlanda (1977, pp. 13-18, 1992, p. 474), De Paolis (1983, pp. 53-144) y Sugawara (1997, p. 53).

[78] "Se il dono fatto al fondatore deve essere accolto, approvato e protetto, questa responsabilità non incombe soltanto all'Istituto: è una responsabilità ecclesiale, che riguarda tutti i fedeli, e in maniera speciale la gerarchia”.

[79] El CIC (Juan Pablo II, 1983, c. 576) recoge lo dicho sobre la tarea de la autoridad de la Iglesia: "Corresponde a la autoridad competente de la Iglesia interpretar los consejos evangélicos, regular con leyes su práctica y determinar mediante la aprobación canónica las formas estables de vivirlos, así como también cuidar por su parte de que los institutos crezcan y florezcan según el espíritu de sus fundadores y las sanas tradiciones".

[80] "The specific nature of each institute is determined and constituted by its founders and approved by the positive will of the Church through her hierarchy institutionally constructed. The hierarchy does not create the state of consecrated life but presents and offers it to God in the name of the Church. The consecration of this state does not exist because it is approved but it is approved because it exists in the Church as a gift of the Holy Spirit. [...] charism is given by divine initiative, the approval by the ecclesiastic authority is a recognition of the authenticity of it".

[81] "Il carisma collettivo diventa un istituto canonico nella Chiesa nel momento in cui essa ne riconosce l'utilità per la sua missione specifica e ne approva la regola. L'approvazione della Chiesa, per mezzo di coloro che hanno il carisma-ministero di discernere tutti i carismi, è necessaria affinché tutto cooperi al bene della Chiesa e perché sia protetto ciò che Cristo ha voluto lasciare alla sua Chiesa per mezzo del carisma generale della sua sequela mediante la professione dei consigli evangelici, e sia mantenuto vivo il dono che lo Spirito ha fatto suscitando nella Chiesa quel dato carisma particolare”.

[82] Sin pretender hacer una configuración o tipología estricta de los diversos Institutos de Vida Consagrada, el CIC (Juan Pablo II, 1983, c. 577) retoma su fundamento cristológico y, al respecto, señala que: "En la Iglesia hay muchos Institutos de Vida Consagrada que han recibido diversos dones, según la gracia propia de cada uno, pues siguen más de cerca a Cristo ya cuando orando, ya cuando anuncia el Reino de Dios, ya cuando hace el bien a los hombres, ya cuando convive con ellos en el mundo, aunque cumpliendo siempre la voluntad del Padre”.

[83] "L'amministrazione dei beni è anche intimamente collegata con lo stile di vita povero e austero proprio degli istituti di vita consacrata, che si concretizza con il voto di povertà emesso dai suoi membri. Per tale motivo è ugualmente importante determinare lo stile che deve caratterizzare un'amministrazione, cui compete non solo di assicurare costantemente lo sviluppo e l'espansione della missione dell'istituto e il benessere dei suoi membri ma anche di favorire nel modo migliore che sia vissuta la povertà che qualifica i consacrati nella loro sequela di Gesù".

[84] El Concilio Vaticano II habla de la Iglesia peregrinante (Vaticano II, 1964, p. 8) a fin de integrar estas dos realidades: la de lo terreno y lo trascendente, pues, aunque ella se encuentra en el mundo, tiene una meta mayor y, por lo tanto, avanza hacia la patria celeste. Con esto el Concilio también estuvo atento a no caer en un espiritualismo exagerado ni a pensar la Iglesia como un mecanismo de poderío terreno (Vaticano II, 1965c, p. 42). 
[85] "Esige che ognuno di essi stabilisca le norme particolari relative all'uso e all'amministrazione dei propri beni in conformità con le esigenze della povertà religiosa. Si richiede, in pratica, una riflessione sull'amministrazione dei beni negli Istituti Religiosi in generale, cui si dovrà aggiungere l'elaborazione di norme particolari per regolare l'amministrazione dei beni di ogni istituto".

[86] "La missione propria dei membri degli istituti di vita consacrata esige sempre la mediazione dei beni materiali. Ne deriva la necessità di amministrare questi beni con tutta la possibile diligenza. Un'amministrazione appropriata e ineccepibile permette che tale missione si compia nel modo più completo".

\section{Licencia Creative Commons CC BY 4.0}

Cómo citar este artículo: Garceranth Ramos, I. A. (2018). Administración y enajenación de bienes temporales eclesiásticos a la luz del Concilio Vaticano II. Parte II: Lumen Gentium, cap. VI; Presbyterorum Ordinis no. 17, y Perfectae Caritatis no. 13. Universitas Canónica, 35(51). https://doi.org/10.11144/ Javeriana.ucan35 -51.aebt 